\title{
O USO DO GPS EM LEVANTAMENTOS GEOFÍSICOS TERRESTRES
}

\author{
Marcelo Soares Teles Santos ${ }^{1}$ e Nelsi Côgo de Sá1,2 \\ Recebido em 9 setembro, 2005 / Aceito em 8 fevereiro, 2006 \\ Received on September 9, 2005 / Accepted on February 8, 2006
}

\begin{abstract}
From analysis of the GPS positioning of 38 bench marks, in a profile located at São Paulo State, some procedures for GPS use in terrestrial geophysical surveys are suggested. The static relative positioning by dual frequencies receivers, from sessions of 60 minutes, was used as reference. The geodetic coordinates were obtained by using several processing strategies, varying the receiver type (single and dual frequencies), the number of baselines ( 1 and 3 ), the length of baseline ( 2 to $250 \mathrm{~km}$ ) and the session time (10 to 60 minutes). The orthometric heights were obtained in a relative way, using the 5 nearest stations of RGSP. The statistical analysis of residuals of the obtained coordinates and heights with respect to the reference values, generated information about the accuracy of the geodetic positioning by GPS, as a function of analyzed parameters. From the obtained results, the GPS positioning methods were specified to local and regional geophysical surveys, according to its characteristics. Therefore, to obtain an accuracy of $10 \mathrm{~cm}$ from baselines greater than $30 \mathrm{~km}$, dual frequency receivers and sessions greater than 30 minutes must be used. For baselines lower than $30 \mathrm{~km}$, may be used dual or single frequency receivers with 30 minutes sessions.
\end{abstract}

Keywords: GPS positioning, levelling by GPS, geophysical surveys.

RESUMO. A partir da análise do posicionamento por GPS de 38 Referências de Nível, num perfil localizado no Estado de São Paulo, são sugeridos procedimentos de uso do GPS em levantamentos geofísicos terrestres. Como referência, foi realizado o posicionamento relativo estático, com receptores de dupla freqüência, coletando dados durante sessões de 60 minutos. As coordenadas geodésicas foram determinadas por meio de diversas estratégias de processamento, variando o tipo de receptores utilizados (simples e dupla frequêencia), o número de bases (1 e 3), o comprimento das bases (2 a $250 \mathrm{~km}$ ) e a duração da sessão (10 a 60 minutos). As altitudes ortométricas foram determinadas no modo relativo, usando as 5 estações da Rede GPS do Estado de São Paulo (RGSP) mais próximas. A análise estatística dos resíduos das coordenadas e altitudes obtidas, em relação aos valores de referência, gerou informações sobre a acurácia dos posicionamentos geográfico e altimétrico por GPS em função dos parâmetros analisados. Com base nos resultados obtidos, foram definidos os métodos de posicionamento GPS para levantamentos geofísicos locais e regionais, conforme suas características. Assim, para se obter acurácia de $10 \mathrm{~cm}$, com bases maiores de que $30 \mathrm{~km}$, deve-se usar receptores de dupla freqüência e sessões de no mínimo 30 minutos. Com bases menores do que $30 \mathrm{~km}$ podem ser usados receptores de dupla ou simples freqüência e sessões de 30 minutos.

Palavras-chave: posicionamento por GPS, altimetria por GPS, levantamentos geofísicos.

\footnotetext{
${ }^{1}$ Universidade de São Paulo - USP, IAG - Departamento de Geofísica, Rua do Matão, 1226, 05508-900 Cidade Universitária, São Paulo, SP, Brasil. Fone: (11) 3091-4762; Fax: (11) 3091-2801 - E-mail: mstsantos@yahoo.com.br

2E-mail: nelsi@iag.usp.br
} 


\section{INTRODUÇÃ̃O}

Os levantamentos geofísicos terrestres consistem em realizar medições de grandezas físicas na superfície da Terra, com o objetivo de estudar a estrutura e as propriedades físicas, e aplicar na exploração de recursos naturais. Há vários métodos de levantamentos geofísicos, cada um usando o princípio físico ao qual é sensível. Os principais métodos são: gravimétrico, magnético, sísmicos e geoelétricos (Kearey \& Brooks, 1984; Dobrin, 1976).

Nesses levantamentos, são necessários os posicionamentos horizontal e altimétrico dos locais das medições para processamento, representação e análise dos dados. Para os posicionamentos, há vários procedimentos disponíveis, tais como mapas topográficos, fotografia aérea, medição de distância e ângulo e os nivelamentos geométrico, trigonométrico e barométrico. A escolha do procedimento deve ser compatível com a precisão desejada, levando-se em conta aspectos econômicos, o tempo necessário e as informações disponíveis (Torge, 1989).

0 uso do Global Positioning System (GPS) gera vários benefícios em relação aos métodos tradicionais de posicionamento. Alguns desses benefícios são: alta precisão, simplicidade operacional, rapidez e baixo custo. Mas, para a adequada utilização do GPS, devem ser adotados critérios relacionados à aquisição e ao processamento de dados, como duração da sessão, tipo de receptores, comprimento e número de bases. Esses critérios são definidos em função das características de cada levantamento (precisão requerida, extensão da área e resolução espacial).

Este trabalho tem como objetivo indicar procedimentos para aplicações do GPS em levantamentos geofísicos terrestres. Para isso, foram posicionadas por GPS 38 Referências de Nível (RNs) localizadas no Estado de São Paulo, numa linha de 250 km de comprimento. As coordenadas geodésicas das RNs foram determinadas por diversas estratégias de processamento, variando 0 tipo de receptor usado (simples e de dupla freqüência), o número de bases utilizadas (1 e 3), o comprimento das bases ( 2 a $250 \mathrm{~km}$ ) e a duração da sessão (10 a 60 minutos). As altitudes ortométricas foram determinadas no modo relativo, usando as estações de referência da Rede GPS do Estado de São Paulo (RGSP) mais próximas, e o modelo geoidal determinado recentemente para a América do Sul (Sá, 2004).

A análise estatística dos resíduos das coordenadas e das altitudes obtidas, em relação às de referência, gerou informações sobre a acurácia dos posicionamentos horizontal e altimétrico por GPS. A partir dessas informações, dos equipamentos e dados disponíveis, e da precisão necessária em cada levantamento geofísico investigado, foram avaliados os resultados obtidos com
0 GPS visando a indicação de sistemáticas para adequação do GPS nessas aplicações.

0 GPS tem sido usado em levantamentos geofísicos como gravimetria regional (Shiraiwa \& Ussami, 2001), gravimetria Iocal e sísmica rasa (Silva \& Pessoa, 1995), sísmica profunda (Perosi, 2000) e magnetometria (Ferraccioli et al., 2001). Entretanto, na maioria desses levantamentos, 0 GPS foi utilizado somente no posicionamento horizontal dos pontos de coleta, com baixa acurácia, exigindo outro método para o posicionamento vertical.

A metodologia e os dados utilizados neste trabalho possibilitaram, com a eficiência e precisão esperadas, aplicações do GPS nos posicionamentos geográfico e altimétrico de todos os levantamentos geofísicos terrestres analisados, usando apenas critérios e informações adequados para aquisição e processamento de dados GPS em função das características dos levantamentos geofísicos.

\section{DADOS UTILIZADOS}

Os dados envolvidos neste trabalho originaram-se de três fontes: rede altimétrica, redes GPS de referência e geóide gravimétrico.

\section{Rede altimétrica}

As RNs pertencentes à Rede Altimétrica Fundamental do Brasil (RAFB) foram implantadas como parte das redes de apoio geodésico para o mapeamento topográfico sistemático do Brasil, pela Fundação Instituto Brasileiro de Geografia e Estatística (IBGE), desde a década de 40. Essas RNs foram implantadas com espaçamento médio de $3 \mathrm{~km}$, ao longo de rodovias e ferrovias. As altitudes das RNs que compõe a RAFB são referidas ao nível médio do mar, dado pelo marégrafo de Imbituba, no Estado de Santa Catarina.

\section{Redes GPS de referência}

Neste trabalho, foram usados os dados de duas redes GPS de referência: a Rede GPS do Estado de São Paulo (RGSP) e a Rede Brasileira de Monitoramento Contínuo (RBMC).

A RGSP, implantada pelo Instituto de Astronomia, Geofísica e Ciências Atmosféricas da Universidade de São Paulo (IAG/USP), é uma rede GPS passiva com de cerca de 200 estações localizadas no Estado de São Paulo e regiões adjacentes (Fig. 1). Essa rede é constituída de RNs, ou seja, cada estação possui coordenadas geodésicas $(\varphi, \lambda, h)$ e altitude ortométrica $(H)$ conhecidas, podendo servir de referência em levantamentos geográfico e altimétrico. Atualmente, a distância máxima entre as RNs dessa 


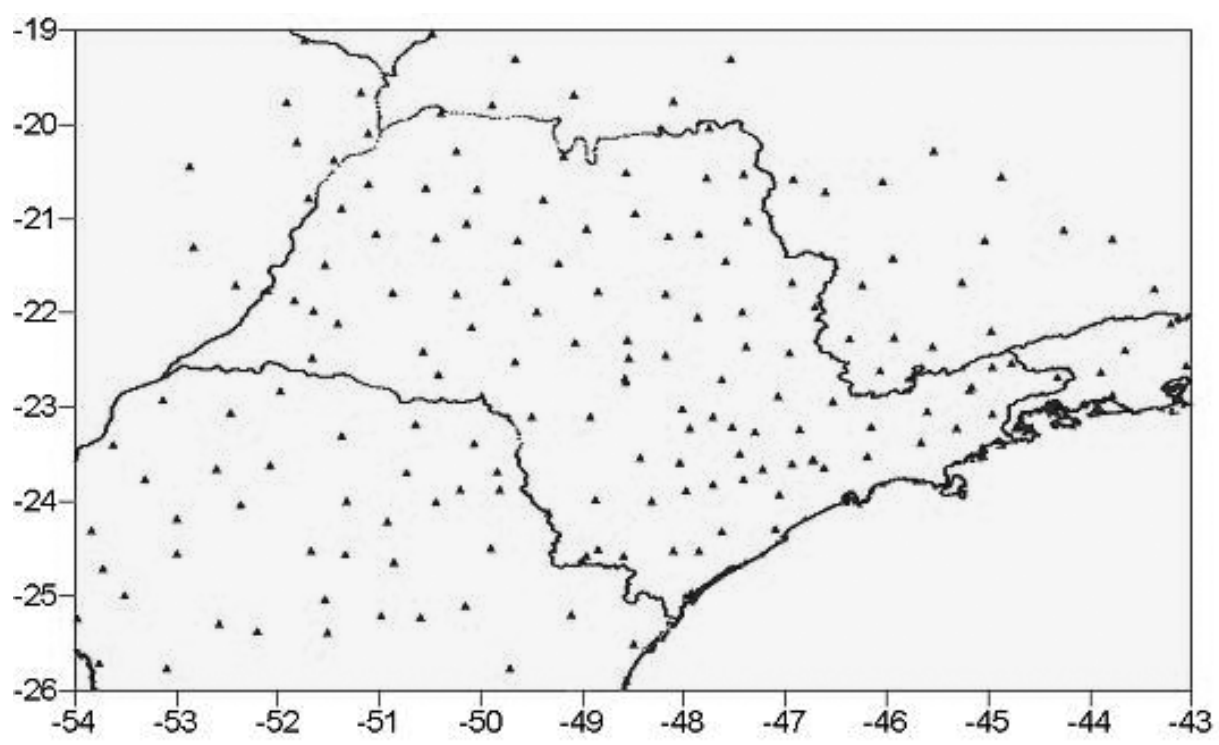

Figura 1 - Rede GPS do Estado de São Paulo - RGSP.

rede é da ordem de $60 \mathrm{~km}$, implicando em bases máximas de $30 \mathrm{~km}$ para o posicionamento relativo GPS em qualquer ponto do Estado de São Paulo (Sá et al., 2001).

A RBMC, implantada e mantida pelo IBGE com a colaboração de várias instituições, é a rede de referência ativa adotada oficialmente no Brasil e possui, atualmente, 20 estações operacionais (Fig. 2). Além de fornecer coordenadas precisas das estações, a RBMC coleta observações dos satélites GPS continuamente nas duas freqüências ( $L 1$ e L2) e disponibiliza alguns dias após a coleta. Isso possibilita a qualquer usuário, com apenas um receptor, realizar o posicionamento relativo. Os arquivos das sessões de observações de cada estação da RBMC, com duração de 24 horas, são disponibilizados no formato RINEX (Receiver Independent data Exchange format), via internet, na página do IBGE (2005). Os arquivos RINEX possuem formato padrão, podendo ser utilizados em qualquer programa de processamento GPS.

\section{Geóide Gravimétrico}

No cálculo das alturas geoidais, foi utilizado o geóide gravimétrico da América do Sul, que possui resolução espacial de $5^{\prime}$ de arco (Fig. 3). Na determinação desse geóide, foi utilizada a colocação por mínimos quadrados, usando o modelo geopotencial EGM96, dados gravimétricos terrestres e oceânicos, e dados topográficos na forma digital (Sá, 2004). As alturas geoidais foram calculadas com auxílio do programa GEOCOM, desenvolvido para 0 uso de modelos digitais (Sá et al., 2001).

\section{METODOLOGIA}

A metodologia aplicada neste trabalho envolveu as seguintes etapas: 1) seleção de um conjunto de RNs para referência; 2) posicionamento GPS das RNs selecionadas; 3) processamento dos dados GPS usando diversas estratégias; 4) avaliação das coordenadas geodésicas obtidas; 5) determinação da altitude ortométrica por GPS das RNs posicionadas; 6) avaliação das altitudes ortométricas; 7) proposição de sistemática para adequação do GPS aos levantamentos geofísicos terrestres a partir dos resultados obtidos. A seguir, são descritas as etapas envolvidas no desenvolvimento do trabalho.

\section{Seleção de RNs para referência}

Para serem usadas como referência na avaliação do posicionamento geográfico e altimétrico por GPS, foram selecionadas 38 RNs pertencentes à RAFB, distribuídas ao longo de uma linha com aproximadamente $250 \mathrm{~km}$ de comprimento (Fig. 4). No extremo inicial da linha, localiza-se a estação Cesário Lange da RGSP, que está distante 380 e 280 km, respectivamente, das estações UEPP (Presidente Prudente - SP) e PARA (Curitiba - PR) da RBMC.

A seleção e posicionamento das RNs foram feitos entre os dias 7 e 17 de março de 2001, com objetivo de avaliar a altimetria por GPS (Castro, 2002). Essas RNs foram selecionadas estrategicamente de acordo com os seguintes critérios: a) espaçamento homogêneo entre as RNs, de 2 a 10 km; b) maior variação nas altitudes das RNs; c) variação gradual da distância entre as RNs e a estação de Cesário Lange (2 a 250 km). 


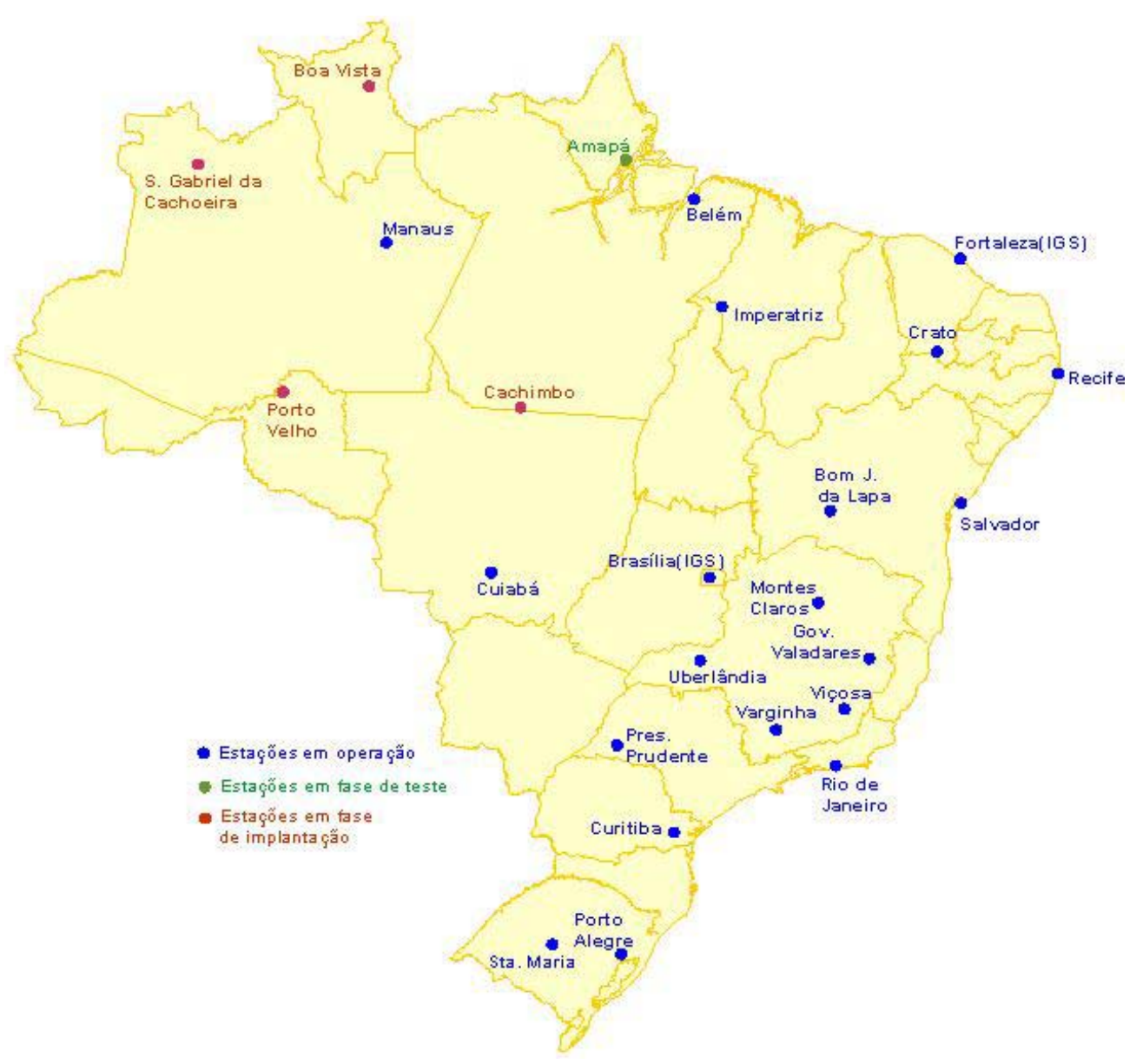

Figura 2 - Rede Brasileira de Monitoramento Contínuo - RBMC.

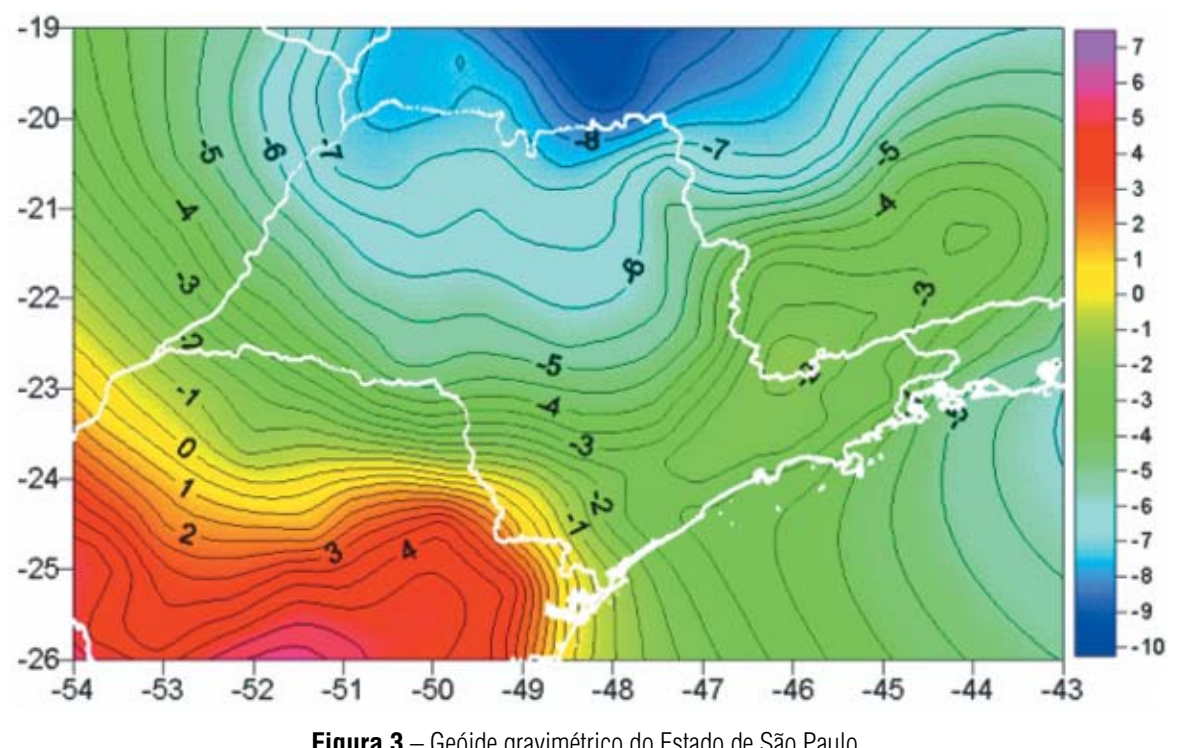

Figura 3 - Geóide gravimétrico do Estado de São Paulo. 


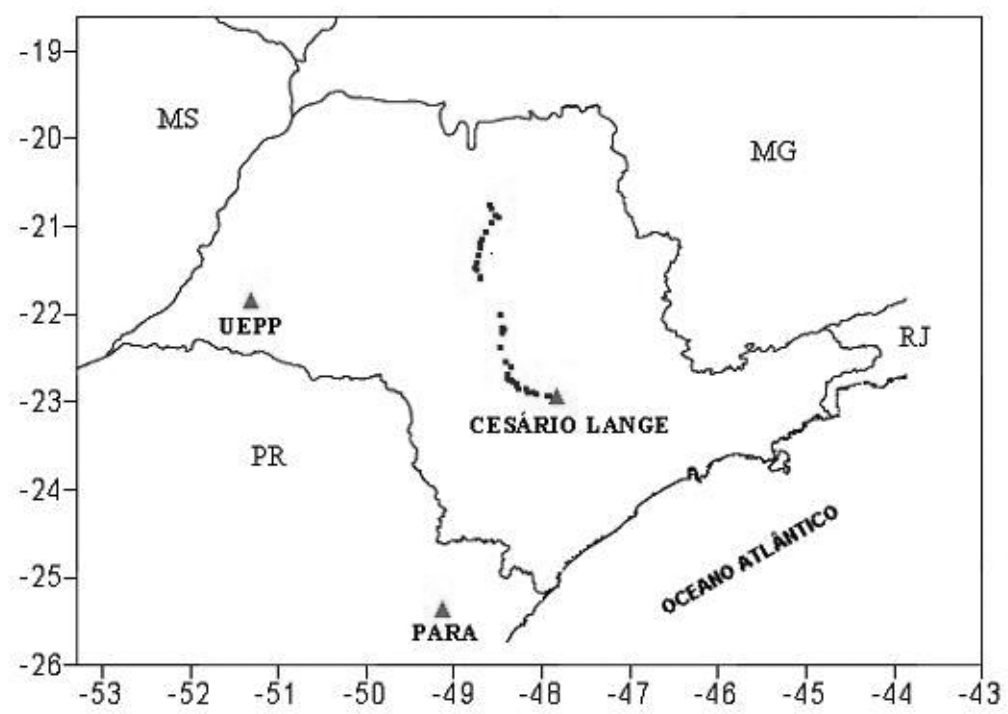

Figura 4 - Localização da área de estudo. Quadrados: RNs selecionadas; triângulos: estações de referência da RBMC e da RGSP.

\section{Posicionamento GPS das RNs selecionadas}

Para posicionar as 38 RNs foi utilizado o posicionamento por GPS no modo relativo estático, no qual dois receptores coletaram dados, simultaneamente, durante um período de 60 minutos; um instalado nas RNs selecionadas e 0 outro na estação de Cesário Lange, adotada como referência no posicionamento (Fig. 4). A distância entre as RNs e a estação de referência variou de 2 a $250 \mathrm{~km}$, permitindo a análise da acurácia do posicionamento relativo em função do comprimento da base.

Após o levantamento de campo, foram obtidos os dados de duas estações pertencentes à RBMC: PARA e UEPP para as mesmas datas e horários das observações (Fig. 4). Esses dados foram usados nos processamentos com o objetivo de analisar a acurácia do posicionamento relativo em função do número de estações de referência. Os dados da RBMC foram copiados via internet, da página do IBGE (2005).

Todos os receptores GPS envolvidos neste experimento, são de dupla freqüência e 12 canais, coletaram dados com intervalo de 15 segundos e ângulo de elevação mínimo de $10^{\circ}$. Os dois receptores usados em campo são do IAG/USP, modelo ASCHTECH Z12, e os da RBMC são modelo TRIMBLE 4000SSI.

\section{Processamento dos dados GPS das RNs}

0 posicionamento relativo estático consiste em receber e armazenar os sinais dos satélites GPS por um determinado período, definido principalmente em função do comprimento e número de bases e do tipo de receptores envolvidos. Com o objetivo de analisar essas variáveis, as coordenadas geodésicas das RNs foram determinadas por 3 estratégias de processamento.

Para a avaliação das coordenadas obtidas com essas estratégias, foram determinadas inicialmente as coordenadas de referência das RNs, já que estas só possuem altitudes ortométricas. Por isso, a seção foi dividida em duas partes: a primeira trata da determinação das coordenadas geodésicas de referência das RNs, e a segunda aborda as estratégias de processamento usadas.

\section{Coordenadas de referência das RNs}

As coordenadas geodésicas de referência das RNs foram determinadas por meio do processamento e ajustamento de todas as sessões de observação, formando uma rede GPS de referência. No processamento dessa rede, os seguintes critérios foram utilizados:

- Freqüência: Lc (combinação de L1 e L2 para reduzir os efeitos da ionosfera);

- Duração da sessão: 60 minutos;

- Intervalo de amostragem: 15 segundos;

- Ângulo de elevação mínimo: $10^{\circ}$;

- Efemérides: precisas;

- Modelo de troposfera: Hopfield. 
No processamento de dados GPS, foram fixadas as coordenadas das estações Cesário Lange, UEPP e PARA. 0 processamento de dados para cada RN proporcionou três vetores independentes, com origem nas estações de referência (Fig. 5). Após o processamento, as observações foram ajustadas em rede, utilizando as componentes dos vetores entre as estações como dados de entrada. Com o ajustamento, as coordenadas geodésicas de cada RN com os respectivos erros padrões foram obtidos.

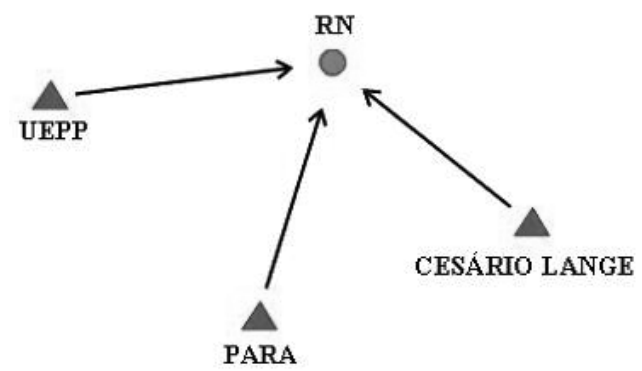

Figura $\mathbf{5}$ - Vetores resultantes do processamento de dados de cada RN.

Os processamentos e ajustamentos foram efetuados com 0 software GeoGenius (SP, 2000).

\section{Estratégias de processamento}

As coordenadas geodésicas das RNs foram determinadas por três estratégias de processamento (Fig. 6):

- Estratégia 1 - base simples, usando a estação Cesário Lange da RGSP como referência e a freqüência L1;

- Estratégia 2 - base simples, usando a estação Cesário Lange como referência e a freqüência Lc (combinação de L1 e L2);

- Estratégia 3 - multiestações, usando as estações Cesário Lange, PARA e UEPP como referências no processamento e ajustamento dos dados e a freqüência LC.

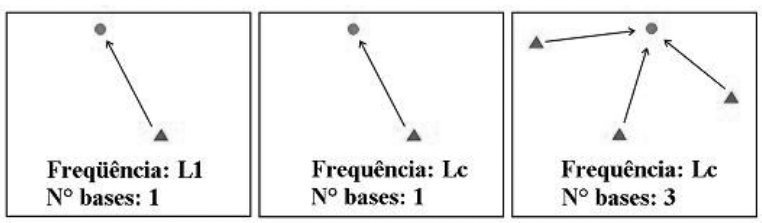

Figura 6 - Estratégias de processamento de dados GPS. Triângulos: estações de referência; círculos: RNs posicionadas.

Todas as sessões de observação (60 minutos) das 38 RNs foram reamostradas e processadas com duração de 10, 20, 30, 40, 50 e 60 minutos, sempre com intervalo de 15 segundos e ângulo de elevação superior a $10^{\circ}$. Nos processamentos, foram usadas as observações da fase da portadora, efemérides precisas e o modelo de troposfera de Hopfield, disponível no sottware de processamento.

As efemérides precisas usadas nos processamentos foram obtidas via internet, na página do International GNSS Service (IGS) (http://www.igs.nasa.gov).

\section{Avaliação das coordenadas geodésicas}

As coordenadas geodésicas obtidas nos processamentos e ajustamentos foram avaliadas pela análise estatística dos resíduos em relação às coordenadas de referência. Para cada RN posicionada $\left(R N_{i}\right)$, foram obtidos os resíduos em latitude $\left(\Delta \varphi_{i}\right)$, longitude $\left(\Delta \lambda_{i}\right)$ e altitude geométrica $\left(\Delta h_{i}\right)$ :

$$
\begin{aligned}
\Delta \varphi_{i} & =\varphi_{r}-\varphi_{i} \\
\Delta \lambda_{i} & =\lambda_{r}-\lambda_{i} \\
\Delta h_{i} & =h_{r}-h_{i}
\end{aligned}
$$

onde os subscritos $r$ e $i$ representam, respectivamente, o valor de referência e 0 valor observado na RN.

\section{Altimetria por GPS nas RNs selecionadas}

\section{Altimetria por GPS}

A altimetria por GPS (Fig. 7) consiste em determinar a altitude ortométrica do ponto de interesse $(i)$ em relação a, pelo menos, uma estação de referência $(A)$, de coordenadas geodésicas $\left(\varphi_{A}, \lambda_{A}, h_{A}\right)$ e altitude ortométrica $\left(H_{A}\right)$ conhecidas. Isso é realizado pela relação entre as diferenças de altitudes geométricas $\left(\Delta h_{i}=h_{i}-h_{A}\right)$, estas determinadas pelo posicionamento relativo por GPS, e de alturas geoidais $\left(\Delta N_{i}=N_{i}-N_{A}\right.$ ), determinadas a partir de um modelo geoidal (Featherstone et al., 1998; Ollikainen, 1998):

$$
H_{i}=H_{A}+\Delta H_{i}=H_{A}+\left(\Delta h_{i}-\Delta N_{i}\right)
$$

A propagação das variâncias observacionais fornece diretamente 0 erro padrão de $H_{i}$ :

$$
\sigma_{H_{i}}= \pm \sqrt{\sigma_{H_{A}}^{2}+\sigma_{\Delta h_{i}}^{2}+\sigma_{\Delta N_{i}}^{2}}
$$

onde, $\sigma_{H_{A}}^{2}$ é a variância da altitude ortométrica de $A ; \sigma_{\Delta h_{i}}^{2}$ é a variância da diferenç̧a de altitude geométrica entre o ponto $i$ e 0 ponto $A$, obtida com o GPS; e $\sigma_{\Delta N_{i}}^{2}$ é a variância da diferenç̧a de altura geoidal entre os pontos, obtida com o modelo geoidal.

A metodologia usada neste trabalho consiste em determinar inicialmente as coordenadas geodésicas de cada RN posicionada 


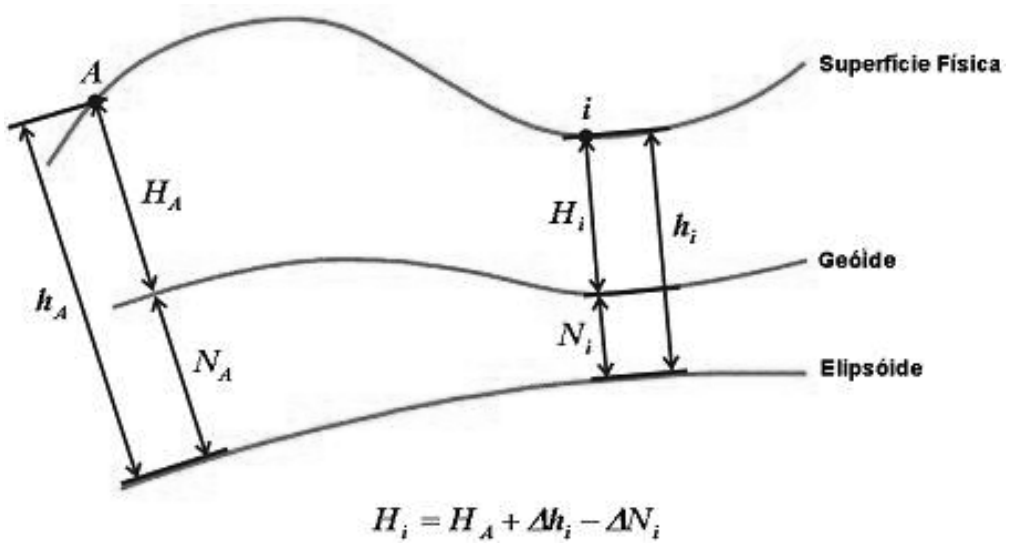

Figura 7 - Altimetria por GPS.

$\left(\varphi_{i}, \lambda_{i}, h_{i}\right)$ e os respectivos erros padrões $\left(\sigma_{\varphi_{i}}, \sigma_{\lambda_{i}}, \sigma_{h_{i}}\right)$, por meio das estratégias de processamento propostas. A partir das coordenadas geodésicas, a altitude ortométrica das RNs são determinadas no modo relativo, usando a equação (4), com a integração dos dados da RGSP e do geóide gravimétrico. A RGSP proporciona estações de referência com coordenadas geodésicas e altitude ortométrica conhecidas; e o geóide fornece as diferenças de alturas geoidais entre as estações de referência e as RNs. 0 erro padrão da altitude determinada é estimado pela equação (5).

Com 0 objetivo de reduzir 0 efeito de eventuais erros grosseiros na altimetria por GPS, as altitudes ortométrica das RNs posicionadas $i=1,2,3, \ldots, n$ foram obtidas a partir das estações de referência $j=1,2,3, \ldots, m$ mais próximas (Fig. 8). Assim, para cada RN posicionada com GPS, resultou um conjunto de altitudes $\left\{H_{1}, H_{2}, H_{3}, \ldots, H_{m}\right\}$ e os respectivos erros padrões $\left\{\sigma_{H_{1}}, \sigma_{H_{2}}, \sigma_{H_{3}}, \ldots, \sigma_{H_{m}}\right\}$. As altitudes das RNs foram determinadas por meio da ponderação daquelas obtidas a partir das estações de referência:

$$
H_{i}=\frac{\sum_{j=1}^{m} P_{j} H_{j}}{\sum_{j=1}^{m} P_{j}}
$$

onde $P_{j}$ é o peso que corresponde ao inverso da variância:

$$
P_{j}=\frac{1}{\sigma_{H_{j}}^{2}}
$$

Na determinação da altitude ortométrica de cada ponto, foram usadas as 5 estações de referência mais próximas. Esse número foi determinado empiricamente a partir de uma análise prévia dos dados observados (Santos, 2005).

\section{Erros padrões}

No cálculo do erro padrão da altitude ortométrica $\left(\sigma_{H_{i}}\right)$, pela equação (5), são necessárias as variâncias $\sigma_{H_{A}}^{2}, \sigma_{\Delta h_{i}}^{2}$ e $\sigma_{\Delta N_{i}}^{2}$, que serão descritas a seguir.

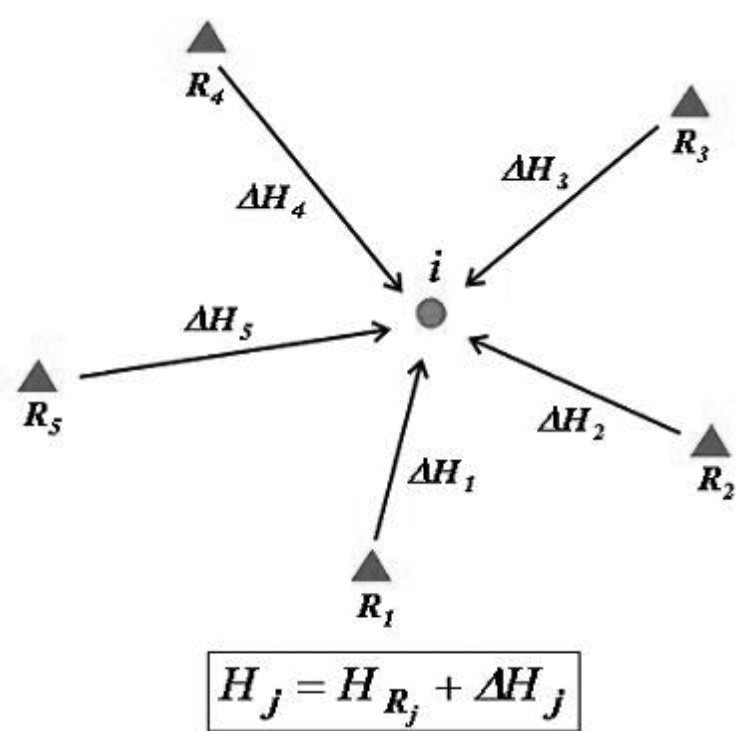

Figura 8 - Altimetria por GPS com superabundância. Triângulos: estações de referência.

\section{Erro padrão das altitudes ortométricas de referência (RNS)}

Como as altitudes ortométricas nas RNs de referência não possuem erros padrões, apesar de serem ajustadas, eles foram estimados a partir da distância ao datum altimétrico de Imbituba, usando o limite da propagação de erros no nivelamento geométrico:

$$
\sigma_{H}= \pm C \sqrt{k}
$$


onde $C$ representa uma constante dada (em milímetros), e $k$, a distância (em quilômetros) da RN de interesse ao datum. Atualmente, o valor de $C$ é $3 \mathrm{~mm}$; porém, em levantamentos mais antigos, era $4 \mathrm{~mm}$. Por isso, foi usada a constante de $4 \mathrm{~mm}$.

A distância $k$ é medida ao longo do trajeto percorrido na implantação da RN, ou seja, corresponde à distância real entre a RN e 0 datum. As distâncias geodésicas entre as estações da RGSP e Imbituba foram calculadas a partir das coordenadas geodésicas dos pontos. Para convertê-las nas distâncias reais, um fator de conversão foi estimado, dado por (Castro, 2002):

$$
F=\frac{d_{A B}}{D_{A B}}
$$

onde, $d_{A B}$ é a distância real entre dois pontos $A$ e $B$ de coordenadas geodésicas conhecidas e $D_{A B}$ é a distância geodésica entre eles.

0 valor de $F$ encontrado por Castro (2002) foi 1, $222 \pm$ 0, 078. Com isso, a expressão (8) assume a forma:

$$
\sigma_{H}= \pm 4 m m \sqrt{1,222 D} \quad \mathrm{~mm}
$$

onde $D$ representa a distância geodésica entre o Datum e a RN.

Pessoa (1995) determinou o mesmo fator de conversão e obteve valor próximo ao encontrado por Castro (2002). 0 valor encontrado pelo autor foi de $1,29 \pm 0,16$.

\section{Erro padrão da diferença de altitude geométrica}

Como a diferença de altitude geométrica entre uma RN posicionada por GPS $(i)$ e uma estação de referência $(j)$ é dada por $\Delta h_{i}=h_{i}-h_{j}, 0$ erro padrão desta diferença foi calculado pela propagação das variâncias observacionais:

$$
\sigma_{\Delta h_{i}}= \pm \sqrt{\sigma_{h_{i}}^{2}+\sigma_{h_{j}}^{2}}
$$

onde $\sigma_{h_{i}}^{2}$ foi determinado com as estratégias de processamento e $\sigma_{h_{j}}^{2}$ é das estações de referência da RGSP.

\section{Erro padrão da diferença de altura geoidal}

Para estimar o erro padrão das diferenças de alturas geoidais, 0 geóide gravimétrico foi avaliado por meio da comparação com as alturas geoidais obtidas por GPS em RNs. Para isso, foram usadas 60 estações da RGSP mais próximas das RNs da linha, as quais possuem coordenadas geodésicas e altitudes ortométricas conhecidas.

A avaliação baseou-se na comparação das diferenças de alturas geoidais obtidas por GPS $\left(\triangle N_{G P S_{U}}\right)$ e as respectivas diferenças obtidas no geóide gravimétrico $\left(\Delta N_{g_{U}}\right)$, em pares de Referências de Nível $R N_{i}$ e $R N_{j}$ :

$$
\delta \Delta N_{i j}=\Delta N_{G P S_{U}}-\Delta N_{g_{U}}
$$

onde

$$
\begin{aligned}
\Delta N_{G P S_{U}} & =\left(h_{i}-H-i\right)-\left(h_{j}-H_{j}\right) \\
& =\Delta h_{i j}-\Delta H_{i j}
\end{aligned}
$$

sendo $\Delta h_{i j}$ e $\Delta H_{i j}$, respectivamente, as diferenças entre as altitudes geométrica e ortométrica entre as RNs; e $\Delta N_{g_{U}}$, a diferença entre as alturas geoidais obtidas com 0 modelo geoidal em avaliação.

A partir das 60 estações usadas na avaliação do geóide, foram obtidas 1770 diferenças de alturas geoidais, com distâncias variando de 3 a $600 \mathrm{~km}$. A partir deste conjunto de dados, foi utilizado o modelo matemático exponencial

$$
Y=a e^{-b x}+c
$$

para representar o erro relativo do geóide, onde $x$ é a distância entre as estações, em km, $y$ é o erro da diferença de altura geoidal, em ppm, $a, b$ e $c$ são os coeficientes determinados pelo método dos mínimos quadrados, e $e$ é a base do logaritmo natural.

Após o ajuste do modelo matemático, os resultados são apresentados na Tabela 1, na qual se tem uma idéia do erro relativo do geóide esperado na prática, com 0 uso do modelo geoidal avaliado.

Tabela 1 - Erro relativo do geóide em função da distância.

\begin{tabular}{|c|c|c|}
\hline Distância $(\mathrm{km})$ & \multicolumn{2}{|c|}{ Erro } \\
\hline & $\mathrm{ppm}$ & $\mathrm{m}$ \\
\hline 1 & 1,248 & 0,001 \\
\hline 5 & 1,221 & 0,006 \\
\hline 10 & 1,188 & 0,012 \\
\hline 20 & 1,124 & 0,022 \\
\hline 30 & 1,064 & 0,032 \\
\hline 40 & 1,007 & 0,040 \\
\hline 50 & 0,953 & 0,048 \\
\hline 60 & 0,902 & 0,054 \\
\hline 70 & 0,854 & 0,060 \\
\hline 80 & 0,808 & 0,065 \\
\hline 90 & 0,765 & 0,069 \\
\hline 100 & 0,724 & 0,072 \\
\hline 150 & 0,550 & 0,082 \\
\hline 200 & 0,418 & 0,084 \\
\hline
\end{tabular}




\section{Avaliação da altimetria por GPS}

As altitudes ortométricas obtidas por GPS foram avaliadas através da análise estatística dos resíduos em relação às altitudes de referência. Para cada RN posicionada foram obtidos os resíduos:

$$
\Delta H_{i}=H_{r}-H_{i}
$$

onde os subscritos $r$ e $i$ representam, respectivamente, a altitude de referência e a altitude determinada na $\mathrm{RN}$.

0 erro padrão de cada resíduo, que indica os limites de variação, foi obtido pela propagação de variâncias:

$$
\sigma_{\Delta H_{i}}= \pm \sqrt{\sigma_{H_{r}}^{2}+\sigma_{H_{i}}^{2}}
$$

onde $\sigma_{H_{r}}$ e $\sigma_{H_{i}}$ foram estimados por (10) e (5), respectivamente.

\section{Adequação do GPS aos levantamentos geofísicos terrestres}

0 resultado da avaliação das coordenadas geodésicas e das altitudes ortométricas obtidas nas estratégias de processamento são seus resíduos em função da duração da sessão, do número e comprimento das bases e do tipo de receptores. A partir destas informações, da precisão requerida e das características de cada levantamento geofísico, são indicados procedimentos de uso do GPS nesses levantamentos.

\section{RESULTADOS E DISCUSSÕES}

Este capítulo apresenta os resultados obtidos no desenvolvimento do trabalho. Na primeira seção são apresentados os resultados referentes ao posicionamento geodésico, ou seja, as coordenadas obtidas nos processamentos de dados GPS. Na segunda seção, os resultados referem-se à altimetria por GPS. A terceira seção faz recomendações para uso do GPS nos levantamentos geofísicos terrestres, conforme os resultados apresentados nas seções anteriores.

\section{Coordenadas geodésicas obtidas com as estratégias de processamento}

As Figuras 9 a 11 ilustram os resíduos das coordenadas geodésicas das RNs, obtidos com a aplicação das 3 estratégias de processamento, e calculados por (1), (2) e (3). No eixo das abscissas, encontram-se as distâncias em relação à estação Cesário Lange, e no eixo das ordenadas, os resíduos.

Analisando as Figs. 9 a 11, verifica-se que, nas 3 estratégias de processamento, a acurácia das coordenadas geodésicas foi proporcional à duração da sessão. Isto ocorreu principalmente porque quanto maior a sessão, maior o número de observações e a variação na geometria dos satélites e, como sugere Rodrigues (2002), melhor é a resolução das ambigüidades. Além disso, quanto maior o período de observação, maior a probabilidade de redução dos efeitos de multicaminho, o qual é dependente da geometria da configuração dos satélites, e menor 0 efeito de uma inadequada geometria dos satélites durante a sessão.

Considerando 0 efeito do comprimento das bases nas observações, nota-se que na estratégia 1 (L1 e 1 base), em todas as sessões, ocorreu grande variação dos resíduos com o aumento da base, deteriorando os resultados para bases maiores do que aproximadamente $30 \mathrm{~km}$. Nas estratégias 2 (LC e 1 base) e 3 (Lc e 3 bases), a acurácia das observações praticamente não se alterou com o comprimento da base. Portanto, conclui-se que, para bases maiores do que $30 \mathrm{~km}$, deve-se usar receptores de dupla freqüência; para bases menores do que $30 \mathrm{~km}$, pode-se usar receptores de simples ou dupla freqüência.

0 comportamento dos resíduos em relação ao comprimento da base evidencia 0 efeito da ionosfera nas observações GPS, que é, atualmente, a maior fonte de erro do sistema GPS. No posicionamento relativo com receptores de simples freqüência e bases de poucas dezenas de quilômetros, os erros devidos ao efeito da ionosfera são praticamente eliminados, por serem altamente correlacionados nas duas estações. Porém, com 0 aumento da distância entre os receptores, os erros apresentam uma redução da correlação, passando a ser proporcionais ao comprimento da base. Os receptores de dupla freqüência permitem reduzir 0 efeito da ionosfera, com a combinação das duas freqüências, para bases de até centenas de quilômetros.

Fonseca Jr. (2002) analisou o comportamento da ionosfera no Brasil através do conteúdo total de elétrons (TEC). Nesse estudo, o comportamento anual do TEC indicou dois períodos de valor máximo, abrangendo os meses de março e abril e de setembro e outubro, coincidindo com os Equinócios de outono e de primavera, respectivamente. Portanto, a atividade solar máxima coincidiu com a época da campanha de observações (7 a 17 de março de 2001).

Comparando as Figuras 10 e 11, observa-se que em todas as sessões, os resíduos obtidos na estratégia 2 foram superiores aos obtidos na estratégia 3, comprovando que 0 ajustamento das observações melhorou a acurácia do posicionamento. Como mostrado anteriormente, em sessões envolvendo mais de uma base, é possível efetuar o ajustamento das observações, permitindo detectar e eliminar possíveis erros grosseiros nos dados, e gerar coordenadas mais consistentes. 

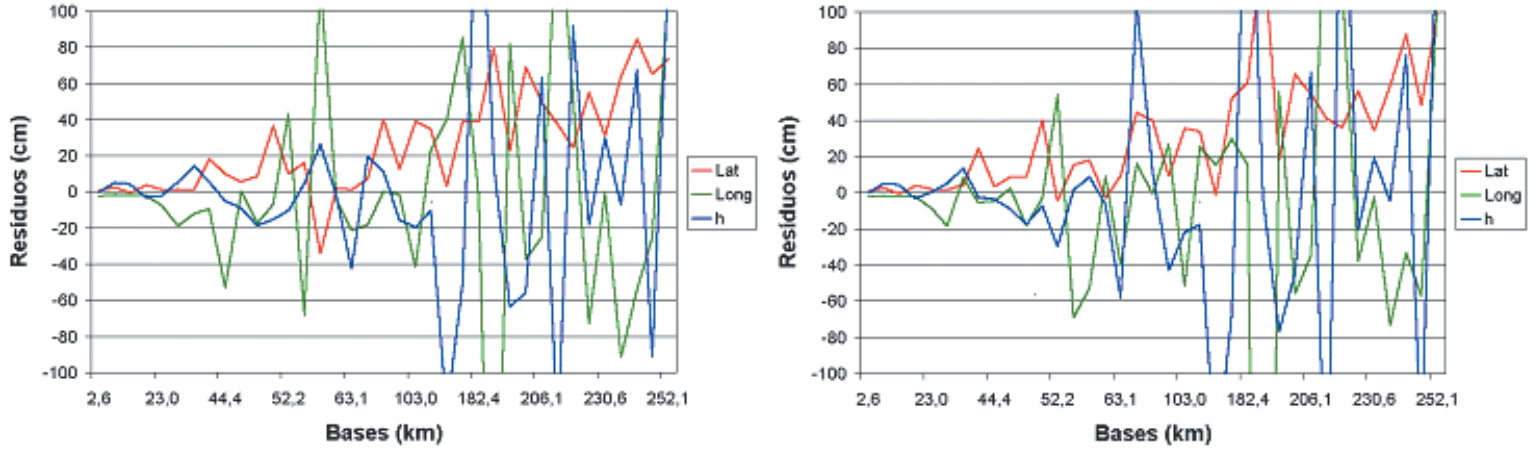

a) com sessão de 60 minutos.

b) com sessão de 50 minutos.
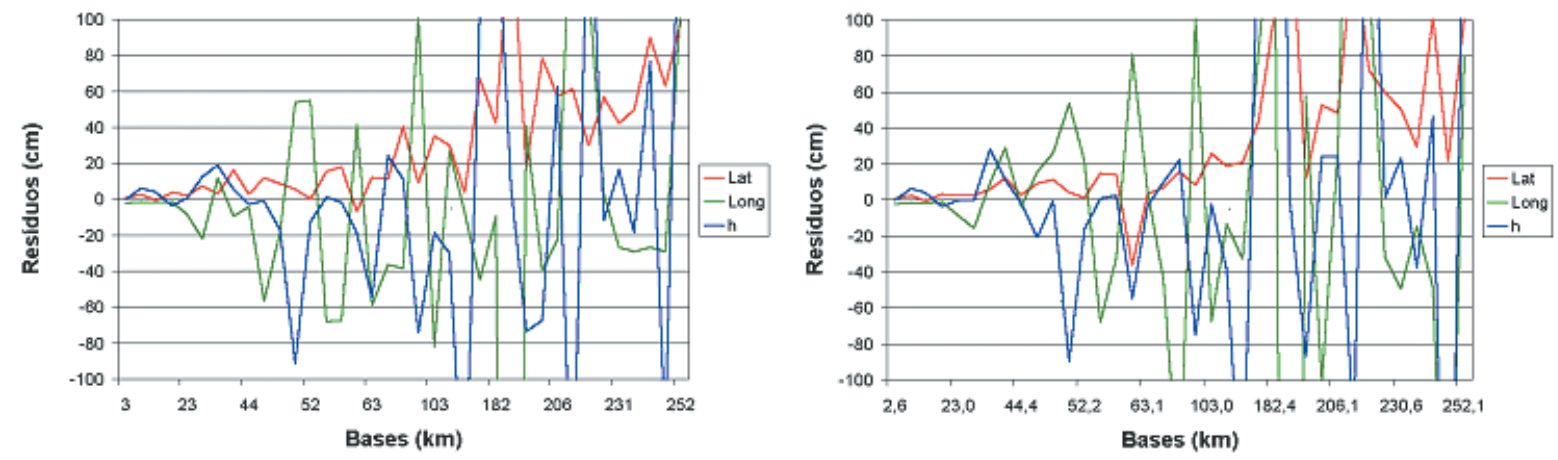

c) com sessão de 40 minutos.

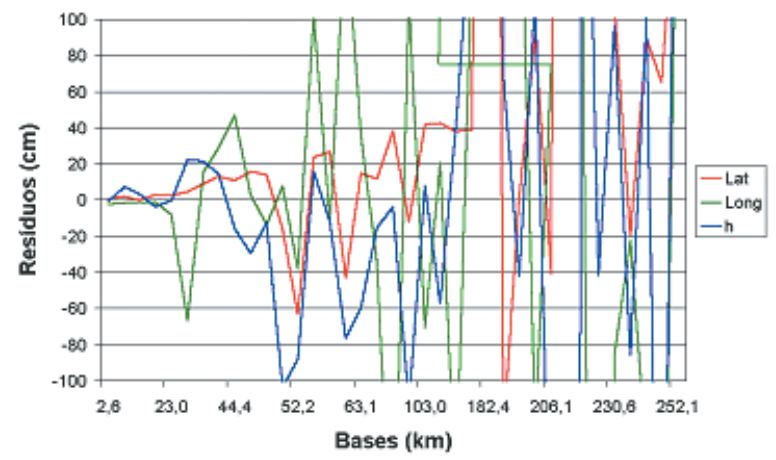

e) com sessão de 20 minutos.

d) com sessão de 30 minutos.

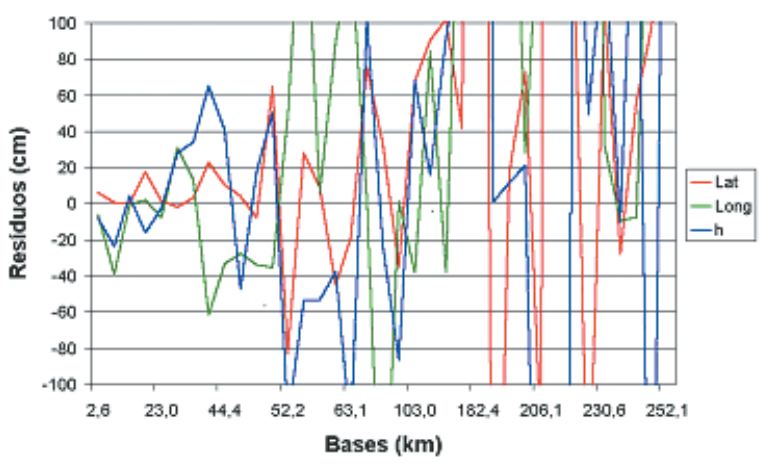

f) com sessão de 10 minutos.

Figura 9 - Resíduos das coordenadas geodésicas obtidas com a estratégia 1 ( $L 1$ e 1 base).

\section{Altitudes ortométricas obtidas com as estratégias de processamento propostas}

As Figuras 12 a 14 ilustram os resíduos das altitudes ortométricas das RNs e os respectivos erros padrões, obtidos com a aplicação das três estratégias de processamento, e calculados por (15) e (16). Para comparação, também são apresentados os resíduos das altitudes geométricas, calculados por (3). No eixo das abs- cissas, encontram-se as distâncias em relação à estação Cesário Lange e no eixo das ordenadas, os resíduos.

Analisando-se as Figs. 12 a 14, verifica-se que nas 3 estratégias de processamento, as altitudes ortométricas alcançaram, praticamente, a mesma margem de erro das altitudes geométricas e apresentaram comportamento idêntico em relação à duração da sessão e ao comprimento da base, ou seja, nas três estratégias, a acurácia foi proporcional à duração da sessão; na estratégia 1, 


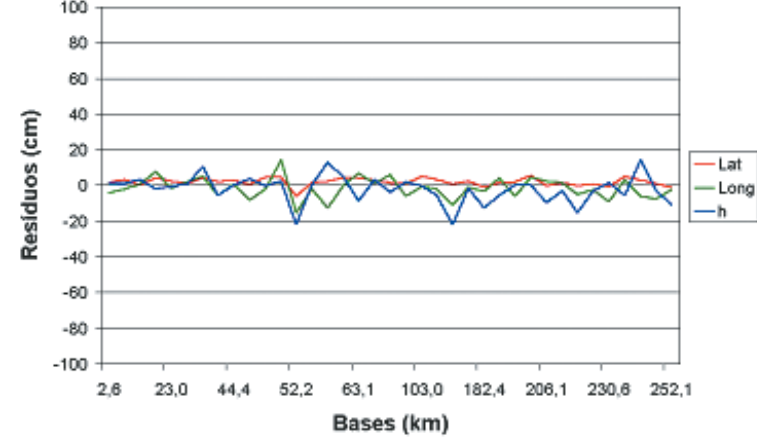

a) com sessão de 60 minutos.

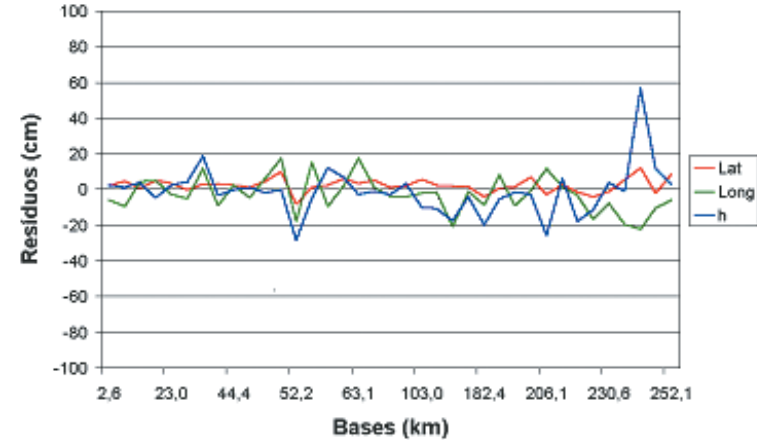

c) com sessão de 40 minutos.

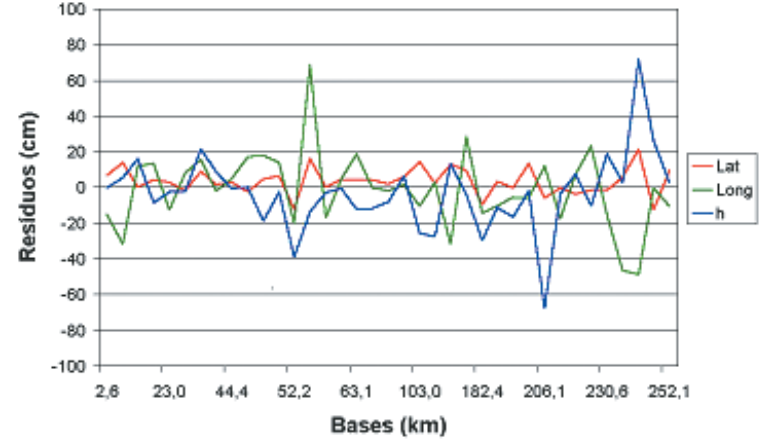

e) com sessão de 20 minutos.

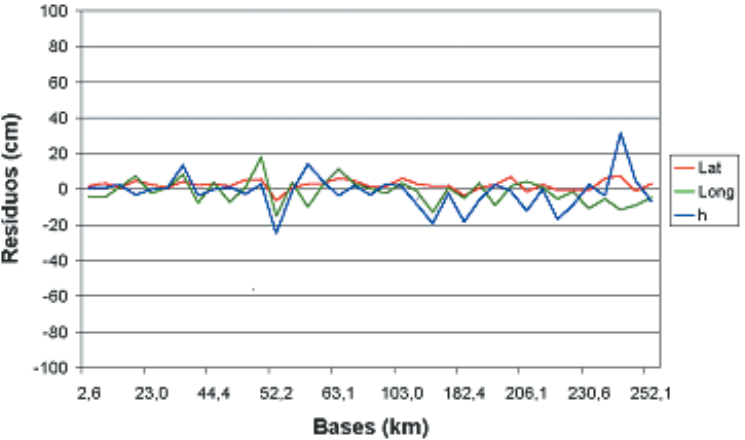

b) com sessão de 50 minutos.

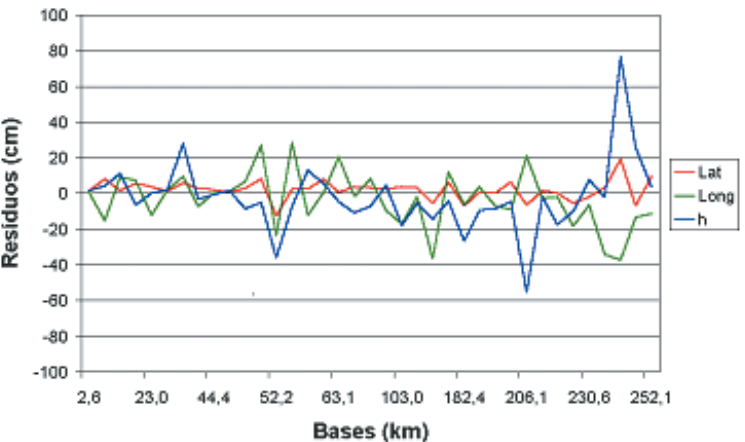

d) com sessão de 30 minutos.

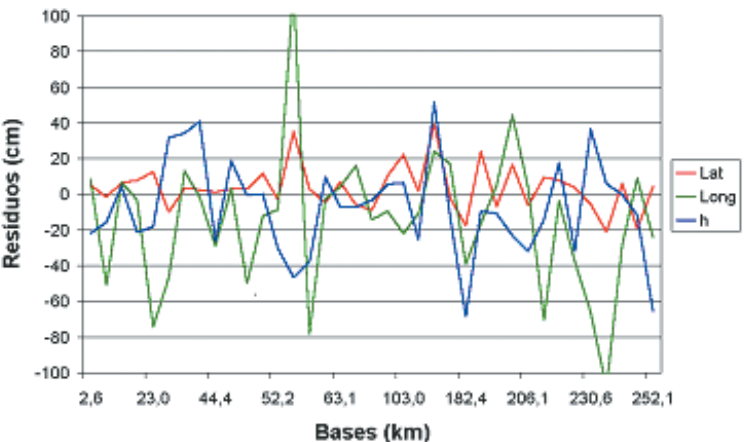

f) com sessão de 10 minutos.

Figura 10 - Resíduos das coordenadas geodésicas obtidas com a estratégia 2 (LC e 1 base).

em todas as sessões, ocorreu grande variação dos resíduos com 0 aumento da base, deteriorando-se os resultados obtidos para bases maiores do que aproximadamente $30 \mathrm{~km}$; nas estratégias 2 e 3, a acurácia das observações não foi, praticamente, alterada com 0 aumento do comprimento da base.

Os resultados mostram que a acurácia das altitudes ortométricas é, praticamente, dependente da acurácia das altitudes geométricas obtidas por GPS.
Isso resultou da alta densidade de estações da RGSP, a qual permitiu 0 uso de bases curtas e médias na altimetria por GPS, proporcionando alta acurácia nas diferenças de alturas geoidais. Santos (2005) mostrou que, usando-se cinco estações de referência, a distância média das estações a cada RN foi de 40 km, e 0 erro estimado na diferença de altura geoidal, de $4 \mathrm{~cm}$. Além disso, foram usadas as estações da RGSP mais próximas das RNs de referência, possibilitando a redução do efeito de 


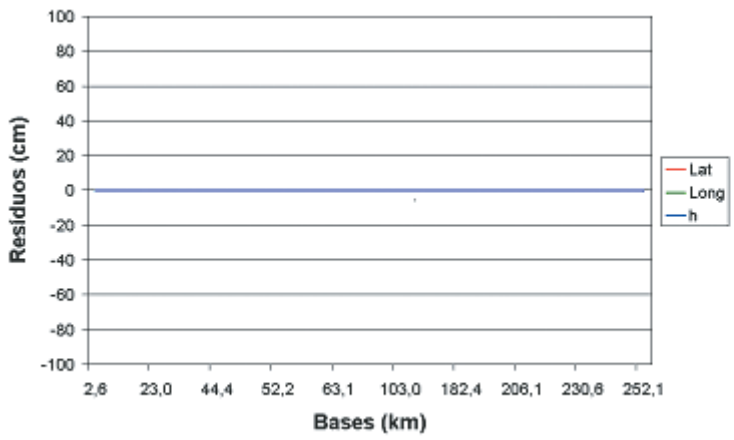

a) com sessão de 60 minutos.

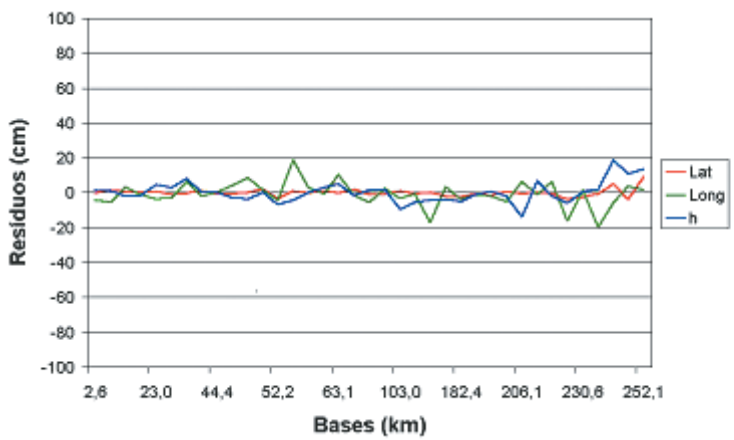

c) com sessão de 40 minutos.

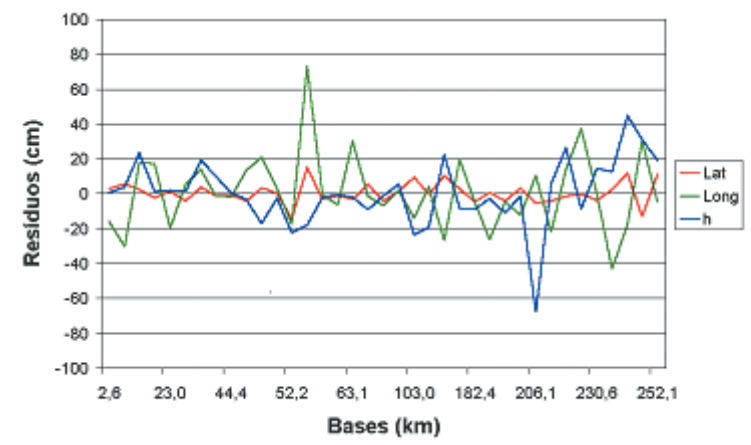

e) com sessão de 20 minutos.

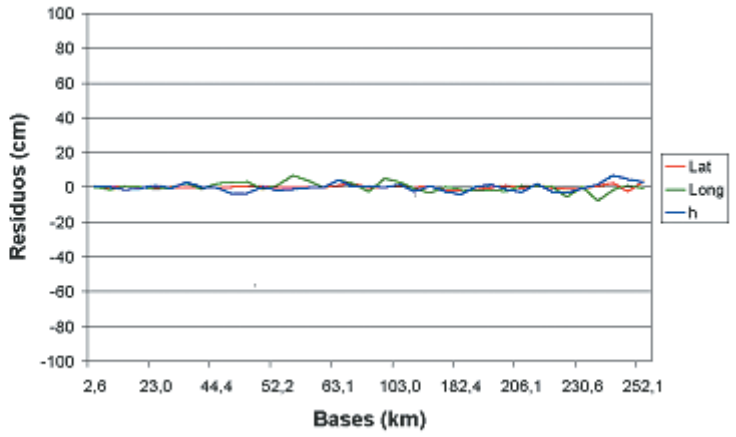

b) com sessão de 50 minutos.

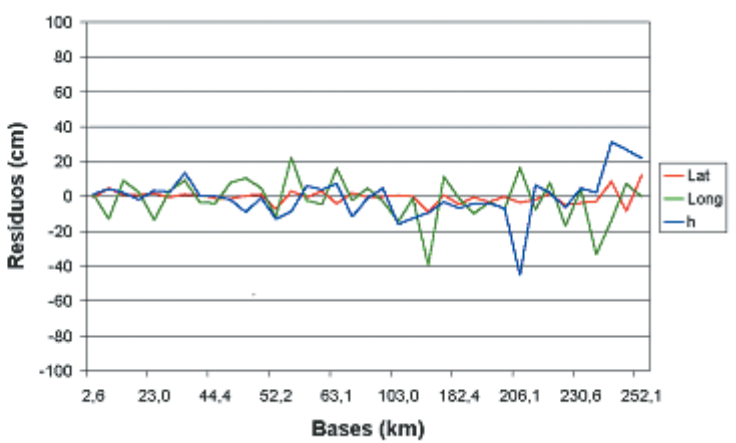

d) com sessão de 30 minutos.

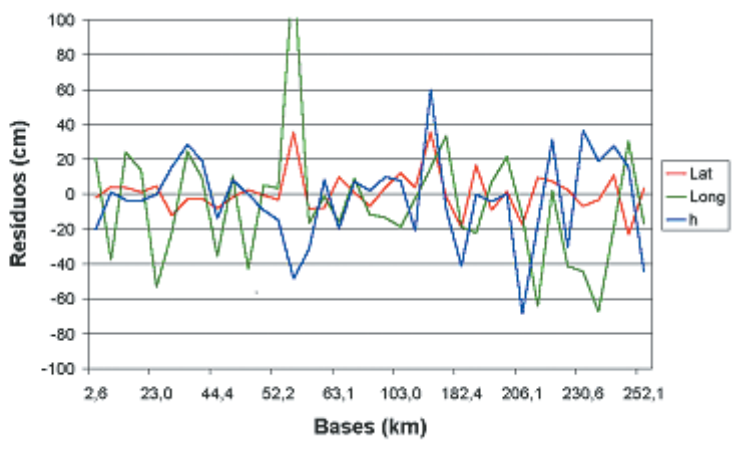

f) com sessão de 10 minutos.

Figura 11 - Resíduos das coordenadas geodésicas obtidas com a estratégia 3 (Lc e 3 bases).

distorções nas altitudes.

Como as estações da RGSP na área de estudo (Fig. 4) estão a cerca de $630 \mathrm{~km}$ do Datum altimétrico de Imbituba, os erros padrões obtidos nas altitudes ortométricas de referência, estimados a partir da expressão (10), foram de 0,11 m. No entanto, em RNs relativamente próximas, por exemplo a 50 km de distância, obtém-se um erro relativo estimado de 0,03 m. Nas altitudes geométricas das estações da RGSP, o erro padrão médio é de $0,05 \mathrm{~m}$.
Os erros padrões dos resíduos das altitudes ortométricas determinadas indicam os erros esperados na altimetria por GPS. Portanto, as discrepâncias entre os resíduos e seus erros padrões podem ser associados a erros envolvidos na altimetria. Comparando-se os resíduos obtidos com os respectivos erros padrões, apresentados nas Figs. 12 a 14, constata-se que as discrepâncias aumentam nas situações nas quais os erros sistemáticos do sistema GPS são maiores, como ocorre nas menores durações de sessões (nas três estratégias) e nos longos compri- 


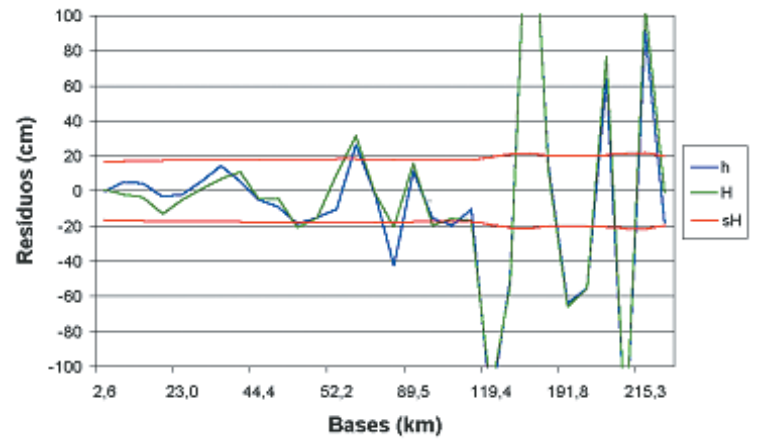

a) com sessão de 60 minutos.

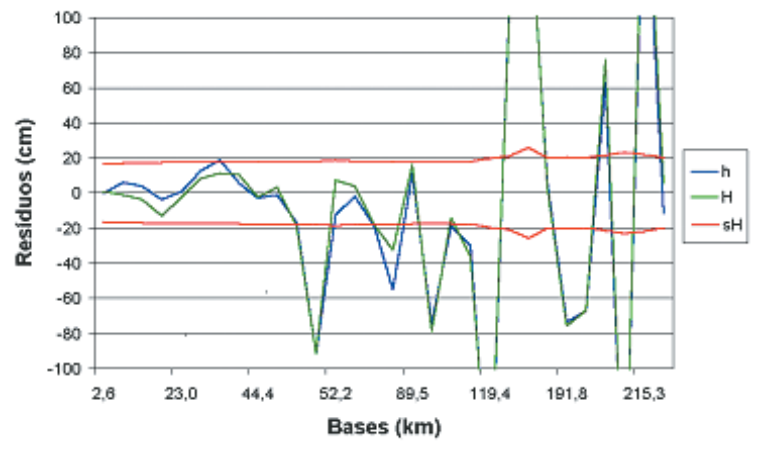

c) com sessão de 40 minutos.

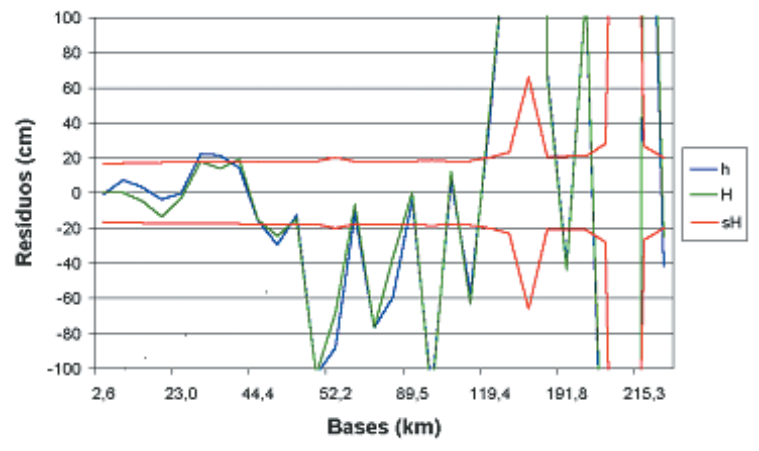

e) com sessão de 20 minutos.

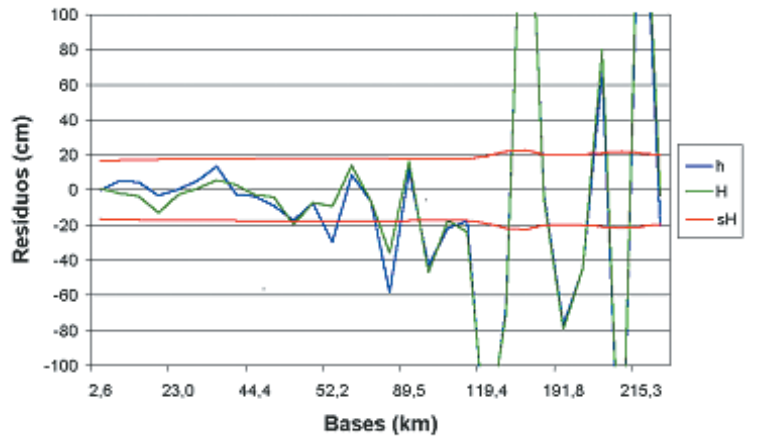

b) com sessão de 50 minutos.

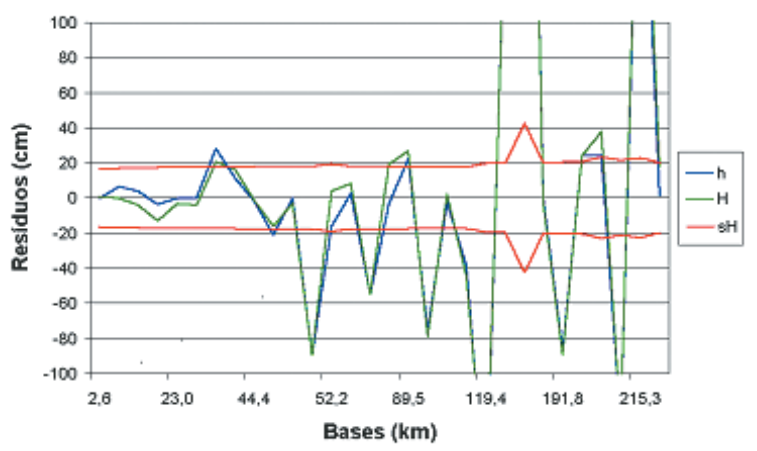

d) com sessão de 30 minutos.

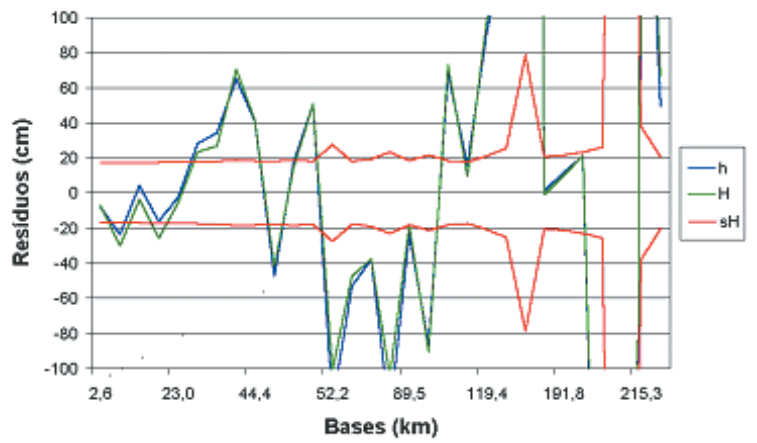

f) com sessão de 10 minutos.

Figura 12 - Resíduos das altitudes ortométricas obtidas com a estratégia 1 (L1 e 1 base).

mentos de bases (na estratégia 1). Portanto, não se pode associar essas discrepâncias a erros na altimetria por GPS, mas às altitudes geométricas obtidas por GPS.

As Figuras 9 a 14 apresentam a acurácia das coordenadas geodésicas obtidas com GPS, em função do comprimento da base, da duração da sessão, do tipo de receptores e do número de estações de referência utilizadas. A partir destas informações, procedimentos de uso do GPS nos levantamentos geofísicos terrestres serão descritos, de acordo com a precisão requerida e as características de cada levantamento.

\section{Recomendação de estratégias}

Nos levantamentos empregando GPS é fundamental o planejamento da campanha de observações, que envolve as seguintes fases: obtenção de informações da região em estudo, como mapas topográficos e dados das estações de referência disponíveis; seleção dos melhores horários para o posicionamento; e escolha das sistemáticas de coleta e processamento de dados. Os resul- 


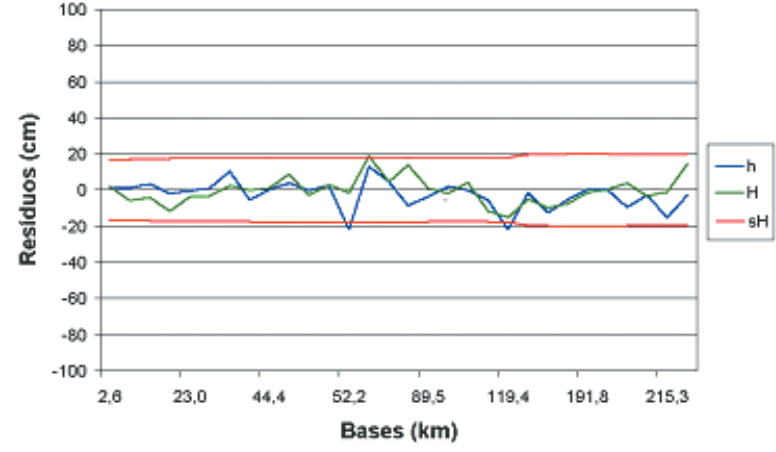

a) com sessão de 60 minutos.

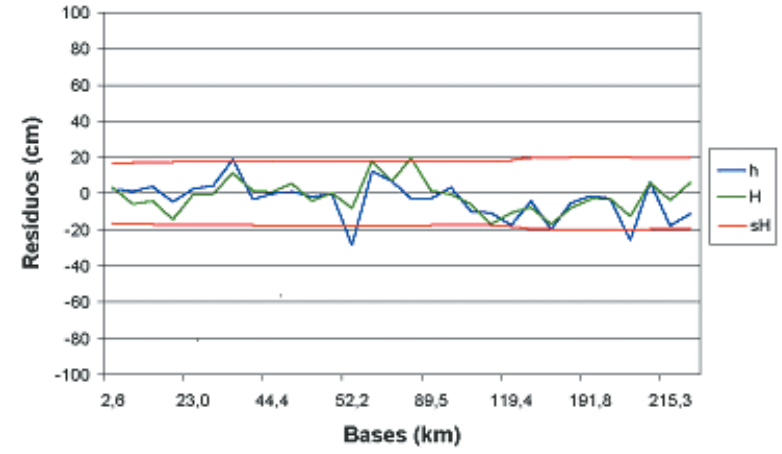

c) com sessão de 40 minutos.

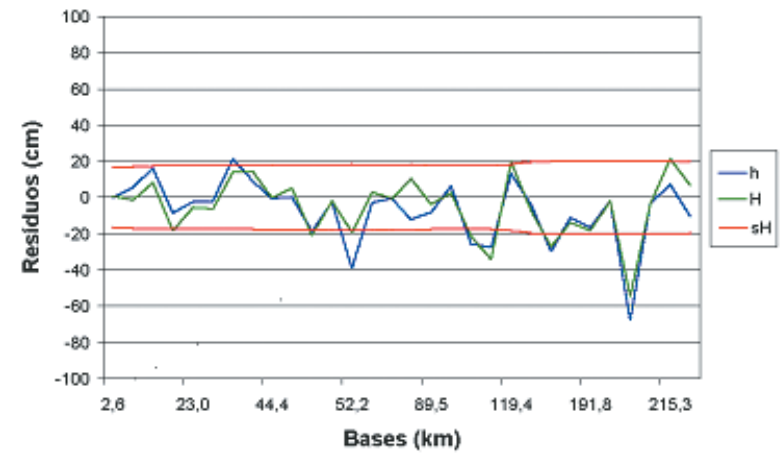

e) com sessão de 20 minutos.

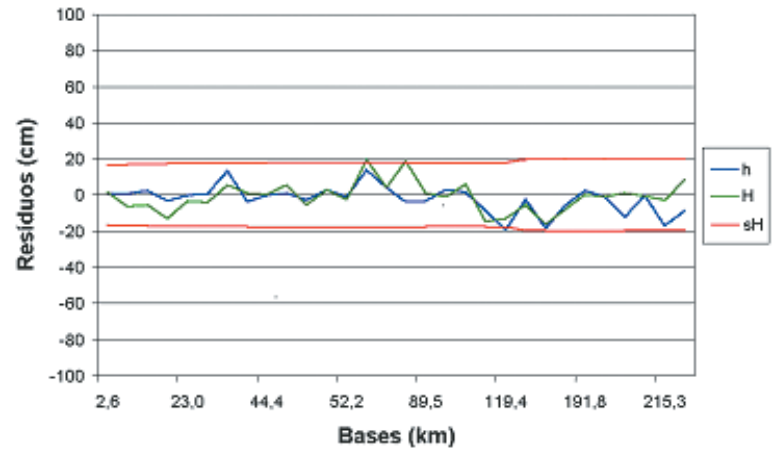

b) com sessão de 50 minutos.

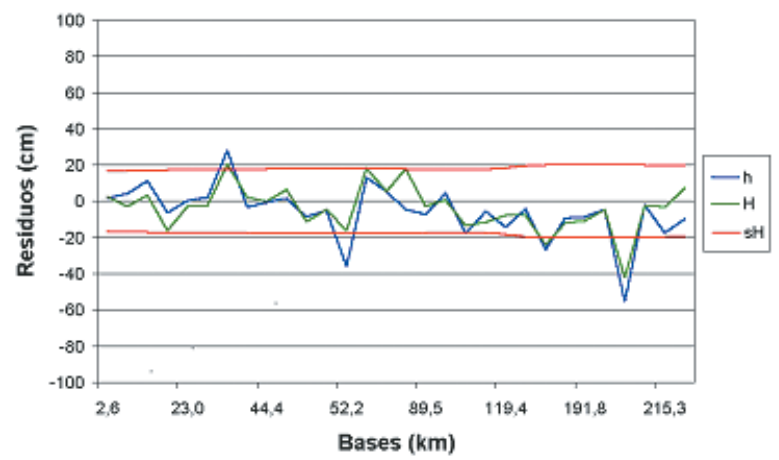

d) com sessão de 30 minutos.

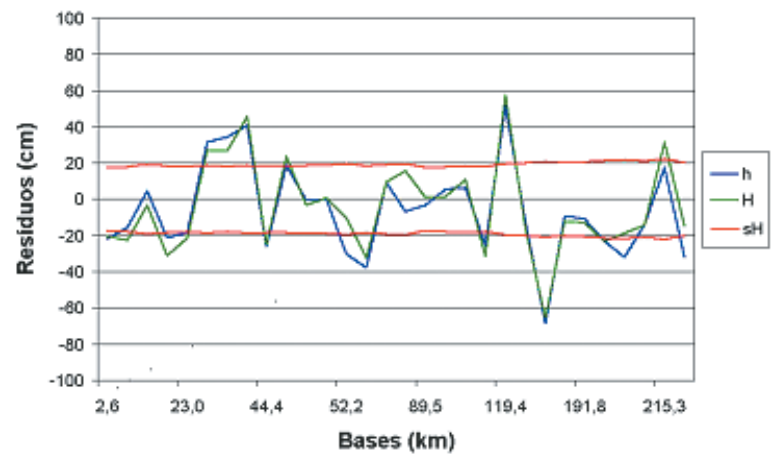

f) com sessão de 10 minutos.

Figura 13 - Resíduos das altitudes ortométricas obtidas com a estratégia 2 (Lc e 1 base).

tados alcançados em qualquer campanha de observações GPS relacionam-se com estas fases.

\section{Planejamento do levantamento com GPS}

Hofmann-Wellenhof et al. (1994) sugerem que o planejamento de uma campanha para coleta de dados GPS deve começar pela obtenção de um mapa da área a ser levantada. Mapas topográficos em escalas 1:50000 e 1:100000 são suficientes para esse propósito. Também é útil a utilização de mapas rodoviários para o conhecimento das vias de acesso aos pontos escolhidos. Loca-se no mapa, os pontos a serem posicionados, Iocalizando as estações da rede de referência mais próxima.

Seeber (1993) e Hofmann-Wellenhof et al. (1994) recomendam critérios para a escolha dos pontos a serem posicionados por GPS: visibilidade do horizonte para ângulos de elevação superiores a $20^{\circ}$; cuidado para evitar a instalação de receptor 


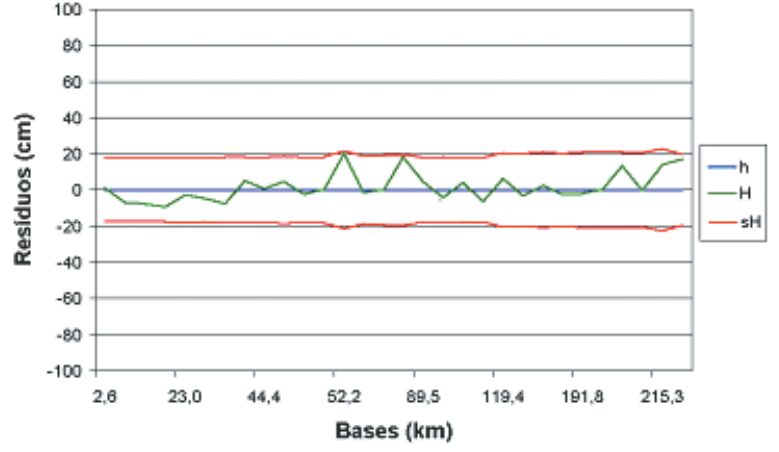

a) com sessão de 60 minutos.

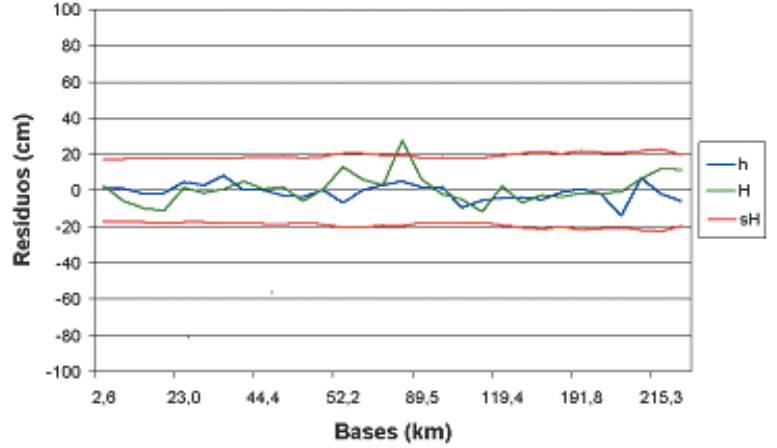

c) com sessão de 40 minutos.

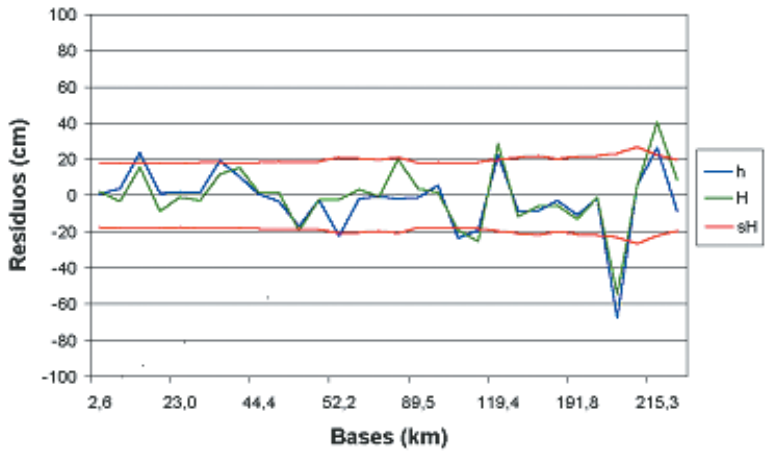

e) com sessão de 20 minutos.

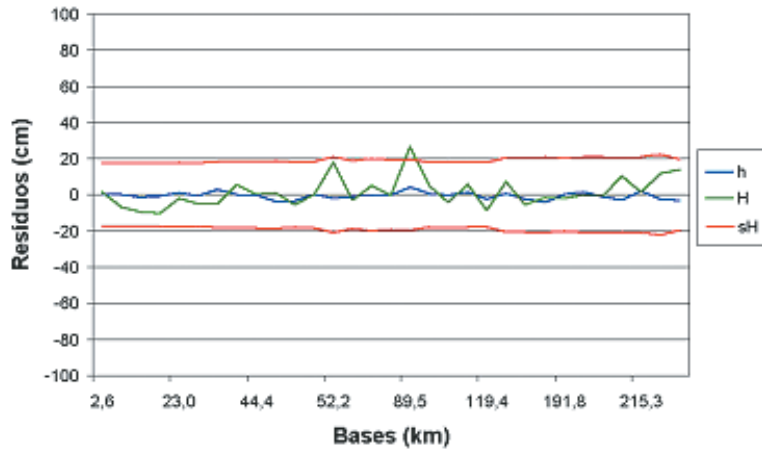

b) com sessão de 50 minutos.

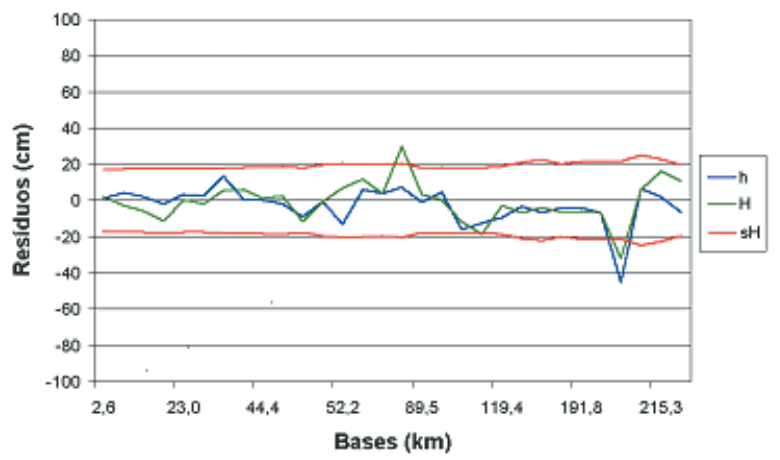

d) com sessão de 30 minutos.

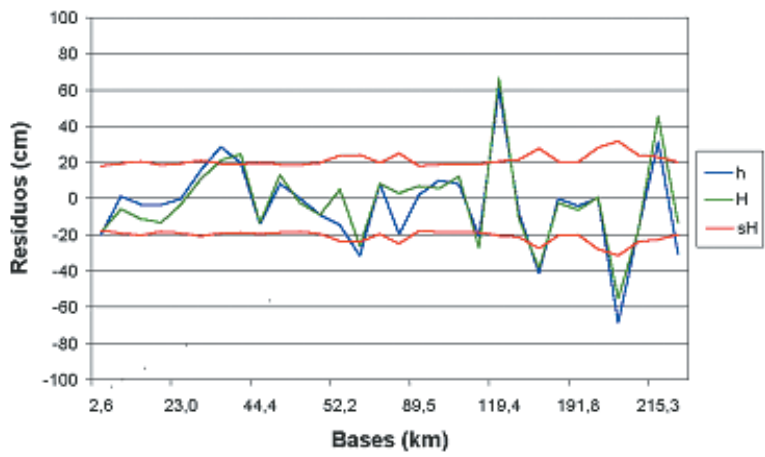

f) com sessão de 10 minutos.

Figura 14 - Resíduos das altitudes ortométricas obtidas com a estratégia 3 (Lc e 3 bases).

próximo a objetos que provoquem reflexão dos sinais emitidos pelos satélites; facilidade de acesso ao local com veículos (para ganhar tempo entre as sessões); locais distantes de redes elétricas de alta tensão, para evitar problemas nos sinais.

Sempre que possível, é recomendável escolher os horários para coleta de dados, usando mapas de PDOP e de número de satélites, para reduzir o efeito da má geometria dos satélites no posicionamento.

\section{Métodos de posicionamento GPS nos levantamentos geofísicos terrestres}

Os principais aspectos a serem considerados na coleta de dados GPS são a eficiência e a economia, que dependem das características do levantamento, como precisão requerida, extensão da área, número e densidade de pontos a serem medidos, e dados e equipamentos disponíveis. 
Em levantamentos regionais, como os gravimétricos, magnéticos e sísmicos profundos, o espaçamento entre os pontos de coleta é grande, podendo chegar a dezenas de quilômetros e não é necessária alta acurácia nos posicionamentos. Nesses levantamentos, o método mais adequado para o posicionamento das estações é o relativo estático rápido, com sessões de curta duração ( $<20$ minutos), cujos erros estimados são de alguns decímetros (Figs. 9 a 11).

Nos levantamentos locais, como os sísmicos rasos, elétricos, eletromagnéticos e gravimétricos, o espaçamento entre os pontos de coleta são menores do que nos levantamentos regionais, podendo chegar a decímetros, sendo exigidos posicionamentos com maior acurácia. Nestes levantamentos, dois aspectos devem ser analisados para uso do GPS: a acurácia e a produtividade. Com relação à acurácia, 0 método mais adequado é o relativo estático convencional (> 20 minutos), que chega à precisão decimétrica de forma simples (Figs. 9 a 11).

No entanto, devido ao pequeno espaçamento e ao grande número de pontos em área relativamente pequena, esse método se torna lento, comparado aos outros. Nesse caso, o GPS deve ser usado para implantar estações de referência na área, visando 0 posicionamento dos pontos de medição, com equipamentos topográficos, como, por exemplo, a estação total, a partir das referências. Em perfis locais, pode-se posicionar com GPS somente os pontos extremos. Os intermediários, com a estação total.

\section{Duração da sessão e comprimento da base}

Serão descritos a seguir, com base nos resultados obtidos, os procedimentos a serem adotados na implantação de estações de referência nos levantamentos locais, com a acurácia de 0,1 m, e o posicionamento de pontos de medição nos levantamentos regionais, com acurácia de $0,5 \mathrm{~m}$, conforme o número e tipo de receptores.

\section{Receptores de simples freqüência (L 1)}

Como mostra a Figura 9, para realizar o posicionamento relativo com receptores de simples freqüência, a estação de referência deve estar no máximo a 30 km de distância, pois a partir dessa distância, a acurácia do posicionamento é deteriorada pelo efeito da ionosfera. Se o usuário só dispor de um receptor, deve realizar o posicionamento relativo usando os dados de uma das estações pertencentes a uma rede GPS ativa, no caso do Brasil, a RBMC, descrita anteriormente. No entanto, a atual distribuição geográfica das estações da RBMC dificilmente fornece bases menores do que 30 km de comprimento, restringindo seu número de usuários.
Com 2 receptores de uma freqüência, pode-se instalar um dos receptores no ponto de interesse, e o outro em estação pertencente a uma rede GPS passiva, como a RGSP. No caso da RGSP, a distribuição geográfica das estações permite bases máximas de aproximadamente $30 \mathrm{~km}$ para pontos localizados em toda a extensão da rede.

A duração da sessão é fixada em função da precisão desejada e do comprimento da base mais próxima, o que pode ser feito a partir da Fig. 9 , onde se verifica que, para obter acurácia de $0,1 \mathrm{~m}$ com bases de $30 \mathrm{~km}$, a duração da sessão deve ser de, no mínimo, 30 minutos. Para acurácia de $0,5 \mathrm{~m}$ e bases de $30 \mathrm{~km}, 10$ minutos são suficientes. Para bases maiores, deve-se empregar receptores de dupla freqüência.

\section{Receptores de dupla freqüência (L1 e L2)}

Como indica as Figs. 10 e 11, com apenas um receptor de duas freqüências, 0 usuário pode realizar o posicionamento relativo empregando uma ou mais estações da RBMC, bastando, para isso, instalar o receptor no ponto de interesse e, alguns dias após o levantamento, obter os dados das estações de referência via internet, na página do IBGE. Neste caso, as estações de referência podem estar localizadas a centenas de quilômetros do ponto de interesse, pois com este tipo de receptor, a acurácia do posicionamento sofre pouca variação com 0 aumento do comprimento da base.

Com 2 receptores de dupla freqüência, pode-se realizar o posicionamento de dois pontos, simultaneamente, utilizando uma ou mais estações de referência da RBMC. 0 uso de mais de uma base melhora os resultados, além de permitir a detecção e redução de erros grosseiros nos dados observados, por meio do ajustamento das observações.

A partir das Figs. 10 e 11 pode-se definir a duração da sessão em função da acurácia desejada. Para se obter acurácia de 0,1 m, por exemplo, são necessários 30 minutos de observação com bases da ordem de $300 \mathrm{~km}$. Para acurácia de $0,5 \mathrm{~m}$, são necessários 10 minutos.

Em levantamentos com outros níveis de precisão, as Figs. 9 a 11 podem ser empregados como referência para planejar a duração de sessões em função dos comprimentos das bases disponíveis e do tipo e número de receptores.

Se os receptores disponíveis forem de simples freqüência e não houver estação de controle suficientemente próxima à área do levantamento, podem ser implantadas estações de referência, através de sucessivos posicionamentos relativos a partir da estação de referência mais próxima. 


\section{Procedimentos de campo e processamento de dados}

Os procedimentos de campo que se recomendam são os usados na coleta de dados deste trabalho, tais como a prévia seleção dos locais a serem posicionados, a obtenção de informações da região em estudo, a instalação, orientação e medição da altura da antena, as anotações de campo e a transferência dos dados coletados.

0 usuário pode definir as informações básicas de processamento dos dados conforme as estratégias sugeridas por Santos (2005) sobre ângulo de elevação mínimo, o intervalo de amostragem, o tipo de efemérides, a observação utilizada, etc.

\section{CONCLUSÕES}

As potencialidades do GPS em levantamentos geofísicos terrestres foram avaliadas a partir de um perfil contendo 38 RNs da RAFB. As coordenadas geodésicas dessas RNs foram determinadas por meio de diversas estratégias de processamento, variando os principais parâmetros envolvidos na coleta e no processamento de dados. A altitude ortométrica de cada RN foi determinada no modo relativo, usando várias estações de referência da RGSP, ponderadas em relação aos erros padrões calculados, e um modelo geoidal recente. A partir dos resultados obtidos, dos equipamentos disponíveis e das características de cada levantamento geofísico investigado, foi feita a adequação do GPS, indicando procedimentos a serem adotados.

Os resultados obtidos nos processamentos de dados GPS, apresentados nas Figs. 9 a 11, indicam que: a) a acurácia do posicionamento por GPS é proporcional à duração da sessão; b) para receptores de uma frequêencia, a acurácia é inversamente proporcional ao comprimento da base, sendo que, para bases maiores que 30 km, deve-se usar receptores de dupla freqüência; e c) 0 aumento do número de bases melhora a acurácia do posicionamento, além de garantir maior confiabilidade aos resultados com 0 ajustamento dos dados.

Na altimetria por GPS, os resultados mostram que: a) 0 uso de várias estações de referência melhora a acurácia da altitude ortométrica determinada, por permitir a ponderação das altitudes e reduzir 0 efeito de erros relacionados às distorções da rede altimétrica; b) a acurácia das altitudes ortométricas tiveram a mesma margem de erro das altitudes geométricas, e apresentaram comportamento idêntico em relação à duração da sessão e ao comprimento da base, como indicam as Figs. 12 a 14. Os resultados obtidos na altimetria por GPS comprovam o potencial da RGSP e do geóide gravimétrico na determinação da altitude ortométrica.

Com base nos resultados obtidos, foi definido o método de posicionamento e altimetria por GPS em cada tipo de levantamento geofísico. Para isso, eles foram divididos em locais e regionais de acordo com a precisão requerida, extensão da área e distância entre os pontos de coleta.

Nos levantamentos geofísicos regionais, caracterizados por grande extensão, baixa densidade de pontos de coleta e posicionamentos de alta acurácia, a técnica mais adequada é o posicionamento relativo estático rápido, que envolve sessões de curta duração ( $<20$ minutos) e fornecem acurácia de alguns decímetros (Figs. 9 a 11).

Nos levantamentos geofísicos locais, caracterizados por pequena extensão, alta densidade de pontos de coleta e posicionamentos de maior acurácia do que nos levantamentos regionais, a técnica mais adequada é o posicionamento relativo estático convencional, com sessões relativamente maiores (> 20 minutos), cuja acurácia é de poucos centímetros (Figs. 9 a 11). Devido ao pequeno espaçamento e ao grande número de pontos medidos em áreas relativamente pequenas, é recomendável 0 uso do GPS na implantação de estações de referência na área de trabalho. Os posicionamentos dos pontos de coleta devem ser realizados a partir das estações de referência com o auxílio de equipamentos topográficos como, por exemplo, estação total.

Após a escolha do método a ser usado nos posicionamentos, os parâmetros básicos de coleta e processamento de dados devem ser definidos, tais como a duração da sessão e o comprimento da base, em função dos dados e equipamentos disponíveis, como distâncias às estações de referência mais próximas, tipo e número de receptores. Por exemplo, como indicam as Figs. 9 a 11, para obter-se acurácia de aproximadamente $0,1 \mathrm{~m}$ usando bases maiores que $30 \mathrm{~km}$, deve-se usar receptores de dupla freqüência e sessões de no mínimo 30 minutos. Com bases menores do que $30 \mathrm{~km}$ pode-se usar receptores de dupla ou simples freqüência e sessões de 30 minutos.

A análise dos resultados mostra que 0 GPS pode ser usado nos posicionamentos geodésico e altimétrico dos levantamentos geofísicos, com vários benefícios em relação aos métodos tradicionais, como precisão, eficiência e economia. No entanto, para a adequada utilização do GPS, devem estar disponíveis os dados que permitam o uso dessa técnica: uma rede GPS com estações de referência com coordenadas geodésicas e altitude ortométrica, e um modelo geoidal de alta precisão.

Para que a metodologia avaliada neste trabalho seja acessível aos usuários, devem ser implantadas redes GPS sobre a rede altimétrica fundamental em outras regiões do país, e continuar os levantamentos gravimétricos para 0 aprimoramento de modelos geóidais gravimétricos de alta precisão. Em trabalhos futuros, 
recomenda-se a avaliação das potencialidades dos métodos cinemáticos nos levantamentos geofísicos terrestres. Apesar das limitações de ordem prática, esses métodos de posicionamento GPS podem ser úteis em certos tipos de levantamentos geofísicos.

\section{REFERÊNCIAS}

CASTRO ALP de. 2002. Nivelamento através do GPS: avaliação e proposição de estratégias. Dissertação de Mestrado. Curso de pós-graduação em Ciências Cartográficas da FCT-UNESP, Presidente Prudente-SP, $174 \mathrm{pp}$.

DOBRIN MB. 1976. Introduction to Geophysical Prospecting - McGrawHill, USA, 630 pp.

FEATHERSTONE WE, DENTITH MC \& KIRBY JF. 1998. Strategies for the accurated determination of orthometric heights from GPS. Survey Review, 34: 278-295.

FERRACCIOLI F, COREN F, BOZZO E, ZANOLLA C, GANDOLFI S, TABACCO I \& FREZZOTTI M. 2001. Rifted(?) crust at the East Antarctic Craton margin: gravity and magnetic interpretation along a traverse across the Wilkes Subglacial Basin region. Earth and Planetary Science Letters, 192: 407-421.

FONSECA JR. ES da. 2002. 0 sistema GPS como ferramenta para à avaliação da refração da ionosférica no Brasil. Tese de Doutorado. Curso de pós-graduação em Engenharia de Transportes da EPUSP, São Paulo. $176 p$.

HOFMANN-WELLENHOF B, LICHTENEGGER H \& COLLINS J. 1994. GPS: Theory and practice. Springer - Verlag Wien, N. York, 355 pp.

IBGE. INSTITUTO BRASILEIRO DE GEOGRAFIA E ESTATÍSTICA. 2005 Disponivel em: <http://www.ibge.gov.br>.

KEAREY P \& BROOKS M. 1984. An Introduction to Geophysical Exploration. Blackwell Scientific Publications, California - USA, 299 pp.

OLLIKAINEN M. 1998. Accuracy of GPS levelling. The XIII General Meeting of the Nordic Geodetic Commission. Anais 1: 25-29, Gävle, Sweden.
PEROSI FA. 2000. Refração sísmica profunda no setor Sudeste da Província Tocantins. Dissertação de Mestrado. Curso de pós-graduação em Geofísica do IAG-USP, São Paulo, 115 pp.

PESSOA LM da C. 1995. Avaliação de modelos geoidais na Bacia do Paraná. In: Congresso Brasileiro de Cartografia, XVII, 1995, Salvador. Anais... Salvador: SBC, 1995. 1: 187-195.

RODRIGUES DD. 2002. Rede geodésica de precisão no estado de Minas Gerais: avaliação de diferentes estratégicas de processamento e ajustamento. Tese de Doutorado. Curso de pós-graduação em Engenharia de Transportes da EPUSP, São Paulo.

SÁ NC de. 2004. 0 campo de gravidade, 0 geóide e a estrutura crustal na América do Sul. Tese de Livre Docência. Departamento de Geofísica do IAG-USP, São Paulo, 121 pp.

SÁ NC de, SOUZA SF de, MONICO JFG, CASTRO ALP \& KRUEGER CP. 2001. 0 GPS no Estado de São Paulo: potencialidades, desafios e estratégias. XX Congresso Brasileiro de Cartografia, Porto Alegre, Anais (CD-ROM).

SANTOS MST. 2005. Potencialidades do GPS em levantamentos geofísicos terrestres. Dissertação de Mestrado. Curso de pós-graduação em Geofísica do IAG-USP, São Paulo, 140 pp.

SEEBER G. 1993. Satellite Geodesy: Foundations, methods and applications. Walter de Gruyter, New York, 531 pp.

SHIRAIWA S \& USSAMI N. 2001. Gravity survey of the Pantanal Wetland: data acquisition and processing. Brazilian Journal of Geophysics, 19(3): 315-323.

SILVA GR \& PESSOA LMC. 1995. Ondulação geoidal a partir do GPS uma solução local. XVII Congresso Brasileiro de Cartografia, Salvador, Anais 1: 134-140.

SP (Spectra Precision). 2000. GeoGenius 2000 user's manual. Version 2.1 Release 1. Hohenkirchen-Siegertsbrunn, Germany.

TORGE W. 1989. Gravimetry. Walter de Gruyter, New York, 465 pp.

\section{NOTAS SOBRE OS AUTORES}

Marcelo Soares Teles Santos. Engenheiro Agrimensor pela Universidade Federal de Viçosa (UFV), em 2003, e Mestre em Ciências no programa de pós-graduação em Geofísica do Instituto de Astronomia, Geofísica e Ciências Atmosféricas da USP (IAG/USP), em 2005. Áreas de interesse: Geodésia por satélite, Geodésia física e Gravimetria.

Nelsi Côgo de Sá. Nelsi Côgo de Sá é formado em Matemática pela UFPR (1973), mestre em Geodésia pela UFPR (1979) e doutor em Geofísica pelo Instituto de Astronomia, Geofísica e Ciências Atmosféricas da USP (IAG/USP), em 1988. É Professor Associado no IAG/USP, onde leciona e pesquisa desde 1975. As principais áreas de interesse são Geodésia física, Geodésia por satélite e Gravimetria. 